\title{
SUBSURFACE STRESS PREDICTION USING SEISMIC DATA FOR OIL AND GAS EXPLORATION
}

\author{
Lourenildo W.B. Leite, Wildney W.S. Vieira and Boris Sibiryakov
}

\begin{abstract}
The present paper is part of a project that has for objective the prediction of stress in sedimentary basins, as a contribution to geological and engineering methods and techniques for oil and gas exploration. Such an attractive and important scientific theme is based on the knowledge of the compressional $\left(v_{P}\right)$ and shear $\left(v_{S}\right)$ wave velocities and the densities $(\rho)$ distributions, in order to localize low pressures zones in sedimentary basins. It is rather usual to think and accept that pressure increases continuously with depth, and we show here that this is not the case. The vertical and horizontal pressure variations act as natural pumps that pushes fluids from high to low pressure zones. The major physical parameter for this phenomenon is played by the $\gamma=\frac{v_{S}}{v_{P}}$ ratio discontinuity along the interfaces. Most of the seismic exploration is based on the acoustical wave equation, that results in a knowledge for the compressional wave velocity model. To obtain the shear wave velocity information it is necessary a 3D component sensor survey, and density log information can also be incorporated. Shear wave velocities can also be obtained from VSP technology, and by petrophysical measurements. There are tables and regression models for seismic velocities and densities that can also be incorporated in this prediction. As a result of the $\gamma$ ratio behavior, an anticline is not necessarily the only structural condition for a potential area for oil and gas accumulation. A trap can be present as a horizontal structure if there is a positive $\gamma$ ratio discontinuity, or a negative discontinuity of the Poisson $\sigma$ ratio across the horizontal boundary (lower minus upper values). These physical conditions are responsible for producing a pressure discontinuity, such that there will be a sufficiently lower pressure zone underneath than above the boundary. In this case, the lower horizontal boundary is said to be a fluid attractor surface. In the opposite physical conditions, this boundary does not have fluid attraction properties. For the developed theory implemented here, the example presented here is the 2D Marmousi subsurface model for simpler and direct visualization, but the theory accounts for a 3D case.
\end{abstract}

Keywords: sedimentary basin modeling, pressure prediction, subsurface stress.

RESUMO. 0 presente trabalho faz parte de um projeto que tem por objetivo a predição de tensões em bacias sedimentares, como uma contribuição aos métodos e técnicas da geologia e da engenharia de exploração de óleo e gás. Este assunto científico, atrativo e importante, é baseado no conhecimento das distribuições das velocidades das ondas sísmicas compressionais $\left(v_{P}\right)$ e cisalhantes $\left(v_{S}\right)$ e das densidades $(\rho)$, com a finalidade de se localizar zonas de baixa pressão no subsolo. É muito comum se imaginar e aceitar que a pressão aumenta continuamente com a profundidade, e mostramos aqui que este não é 0 caso. As variações verticais e horizontais de pressão agem como bombas naturais que forçam os fluidos se moverem das zonas da alta para as de baixa pressão. 0 parâmetro físico principal que rege este fenômeno é a medida de descontinuidade representada pela razão $\gamma=\frac{v_{S}}{v_{P}}$ ao longo das interfaces. A maior parte dos métodos sísmicos de exploração é baseada na equação de onda acústica, o que resulta no conhecimento do modelo de velocidade das ondas compressionais. Para se obter a informação das ondas cisalhantes é necessário que o levantamento seja com sensores 3D, e a informação de poço também possa ser incorporada. Velocidades das ondas cisalhantes também podem ser obtidas com a tecnologia VSP, e com medidas petrofísicas. Existem modelos de tabelas e de regressão para velocidades sísmicas e densidades que também podem ser incorporadas na predição. Como resultado do comportamento da razão $\gamma$, um anticlinal não é necessariamente a única condição estrutural para a potencialização de acumulações de óleo e gás. Uma trapa pode estar presente numa estrutura horizontalizada se a descontinuidade na razão $\gamma$ for positiva, 0 que significa uma descontinuidade negativa no coeficiente $\sigma$ de Poisson ao longo da interface (parâmetros da parte inferior menos o da parte superior). Estas condições físicas são responsáveis por produzirem uma descontinuidade de pressão, de forma que existirá uma zona de pressão suficientemente mais baixa sob a interface do que acima dela. Neste caso, a parte inferior da interface é dita ser uma superfície de atração de fluidos. No caso oposto das condições físicas, a interface inferior não tem as propriedades de atração de fluidos. Para a teoria aqui desenvolvida e implementada, o exemplo apresentado é do modelo da bacia do Marmousi 2D para uma visualização mais direta, mas a teoria admite um caso 3D.

Palavras-chave: modelagem de bacia sedimentar, predição de pressão, tensão na subsuperfície.

Universidade Federal do Pará, Campus Universitário do Guamá, Instituto de Geociências, 66075-110 Belém, PA, Brazil.

Phone: +55(91) 3201-7693; Fax: +55(91) 3201-7609 - E-mails: Iwbleite@gmail.com; wildneyvieira@gmail.com; SibiryakovBP@gmail.com 


\section{INTRODUCTION}

This paper is a continuation of a major study for the prediction of subsurface stress and strain using $P$ and $S$ wave velocities $\left(v_{\mathrm{P}}(\mathbf{x}), v_{\mathrm{S}}(\mathbf{x})\right)$ and density $(\rho(\mathbf{x}))$ to localize zones of pressure discontinuity, that act as natural suction pumps in oil and gas productive layers. As a result of these studies, Sibiryakov et al. $(2014,2015)$ are example of publications, and they deal with different aspects of the research studies.

The main question here raised is: How sensitive is the pressure prediction calculus to variations of velocity and density distribution models?

The answer to this inquiry could be given by sensitivity analysis of the problem's differential equation system, or in a more practical way by numerical experiments. We chose this later route based on migration methodology, where testing is performed with smoothed versions of the input a priori information.

To develop the theory for stress-strain prediction for practical application in oil and gas exploration, the first part has to be related to conventional seismic investigations to obtain the $P$ and $S$ wave velocities and densities model. Also, the configuration of seismic boundaries in the sedimentary basins can be necessary. With these informations, the second part follows with the prediction of stress and strain, and of the nontrivial behavior of pressure. As a third continuation part, is the prediction of pressure discontinuity between solid and fluid, that depends on the structure of the pore space.

The present description considers only isotropic models, and the theory also says that it is mandatory the knowledge of $v_{\mathrm{P}}(\mathbf{x})$, $v_{S}(\mathbf{x})$ and $\rho(\mathbf{x})$. For anisotropic cases the equations are more complicated, more control parameters, and the data needs more processing. Since we have discretized the model in uniform 3D grid, the layer cells forming the 3D geological structure have constant elastic parameters.

The data needed for pressure prediction can be 3C (three component sensors) to obtain P and S (SH and SV) wave modes, and density log information can be incorporated. Also $S$ wave velocities can be obtained from VSP technology, and by petrophysical measurements (Galperin, 1985; Biondi, 2010; Hardage et al., 2011).

The theory is based on the static stress-strain equations, where the overload gravity weight is responsible for the strain and stress effects in the subsurface. Therefore, organizing this problem calls for Hooke's generalized law of linear elasticity.

Another approach is to take into consideration the layer interface curvatures, and to model this case as a confined plate (Sibiryakov et al., 2015), what becomes a more complex prob- lem. For instance, the anticline structure can be a very useful trap, especially if it has a negative discontinuity (lower minus upper parameters) in the $\gamma=\frac{v_{S}}{v_{P}}$ ratio. In this case, exists also an additional horizontal stretching due to the negative curvature of the anticline structure. It is interesting, that the effects of the structure slope and curvature contribute in opposite directions; the slopes produce an additional compression, while the average surface curvature (Smirnov, 1964) produces a horizontal stretching. If there is an anticline structure with a positive discontinuity in the $\gamma$ ratio, it can be a compensational effect. The additional pressure due to the $\gamma$ discontinuity, and the additional stretching due to the average curvature may eliminate each other. In this case, the anticline structure is not a fluid attractor.

Basin studies aiming at oil and gas exploration contain many theorectical aspects related to engineering, geology, geochemistry and geophysics, in order to characterize the reservoirs (Hantschel \& Kauerauf, 2009). Ameem (2003) presents a special bibliography for methods and theories on crustal stress studies, and also Zang \& Stephansson (2010) is here used as a systematic reference. But, it should be clear that here we are developing a specific data driven method that is based on $v_{\mathrm{P}}(\mathbf{x}), v_{\mathrm{S}}(\mathbf{x})$ and $\rho(\mathbf{x})$ knowledge, where we would like to map low pressure zones that are important to locate a successful drilling zone for oil and gas exploration.

\section{METHODOLOGY}

\section{The stress and strain tensor fields}

The stress $[\sigma=\sigma(x, y, z)]$ and strain $[\epsilon=\epsilon(x, y, z)]$ linear elastic continuum fields are related by the generalized Hooke's law, and described as tensors, functions of the space coordinates, and they are represented by nine components. Figure 1 illustrates these quantities for an arbitrary Cartesian reference coordinate system $(x, y, z)$, where any other desired plane, $\left(x^{\prime}, y^{\prime}, z^{\prime}\right)$, can be drawn to to have stress and strain calculated. Therefore, for the general anisotropic media the stress $(\sigma)$ and strain $(\epsilon)$ tensors obey the spatial coordinate rotation relation given by:

$$
\sigma_{i j}=\sum_{k, l} a_{i j k l} \sigma_{k l}^{\prime}
$$

and

$$
\epsilon_{i j}=\sum_{k, l} b_{i j k l} \epsilon_{k l}^{\prime},
$$

where the coefficients $a_{i j k l}$ and $b_{i j k l}$ define the new plane with respect to a reference system. The elastic linear relation between stress and strain is given by the generalized Hooke's law (Mavko 
et al., 1999):

$$
\sigma_{i j}=\sum_{k, l} c_{i j k l} \epsilon_{k l}
$$

In this description, the first index $(i)$ in $\sigma_{i j}$ and $\epsilon_{i j}$ stands for the plane direction, and the second $(j)$ for the component direction. It follows that the stress-strain will depend on the plane orientation passing by a considered point $Q$ (see Fig. 1), and calculated by their nine components. As we particularize, the stress state is represented at a point $Q$ by a matrix $\mathbf{S}$, with the elements are $\sigma_{i j}$ :

$$
\mathbf{S}=\left[\begin{array}{ccc}
\sigma_{x x} & \sigma_{x y} & \sigma_{x z} \\
\sigma_{y x} & \sigma_{y y} & \sigma_{x z} \\
\sigma_{z x} & \sigma_{z x} & \sigma_{z z}
\end{array}\right]
$$

The differential equations that follow in the sequel are related to Figure 1 (similar figures can be presented to described strain), that serve to represent a physical particle of the subsurface, and the solution of the equations correspond to the integration over these infinitesimal quantities.

\section{Stress States}

We now look at expressions to represent the stress field. Therefore, turning to the stress matrix (4), it can be decomposed in three parts in the form: $\mathbf{S}=\mathbf{S}_{\mathbf{0}}+\mathbf{S}_{\mathbf{D}}+\mathbf{S}_{\mathbf{N}}$, such that it allows for a physical interpretation (Persen, 1975). For the state $\mathbf{S}_{\mathbf{0}}$ we have that:

$$
\mathbf{S}_{\mathbf{0}}=\left[\begin{array}{ccc}
P_{H} & 0 & 0 \\
0 & P_{H} & 0 \\
0 & 0 & P_{H}
\end{array}\right]
$$

where

$$
P_{H}=\frac{1}{3}\left(\sigma_{x x}+\sigma_{y y}+\sigma_{z z}\right)
$$

with the sum (6) for the normal stresses in Eq. (5) defining the called hydrostatic pressure, and this state is present in any plane around the point $Q$. For the state $\mathbf{S}_{\mathbf{D}}$ we have that:

$$
\mathbf{S}_{\mathbf{D}}=\left[\begin{array}{ccc}
\sigma_{x x}-P_{H} & \frac{1}{2}\left(\sigma_{x y}+\sigma_{y x}\right) & \frac{1}{2}\left(\sigma_{x z}+\sigma_{z x}\right) \\
\frac{1}{2}\left(\sigma_{x y}+\sigma_{y x}\right) & \sigma_{y y}-P_{H} & \frac{1}{2}\left(\sigma_{y z}+\sigma_{z y}\right) \\
\frac{1}{2}\left(\sigma_{x z}+\sigma_{z x}\right) & \frac{1}{2}\left(\sigma_{z y}+\sigma_{y z}\right) & \sigma_{z z}-P_{H}
\end{array}\right] .
$$

For the above Eq. (7), applying the symmetry property: $\sigma_{x y}=\sigma_{y x}, \sigma_{x z}=\sigma_{z x}, \sigma_{y z}=\sigma_{z y}$, $\mathbf{S}_{\mathbf{D}}$ results in a null state; i.e., $\mathbf{S}_{\mathbf{D}}=\mathbf{0}$. For the state $\mathbf{S}_{\mathbf{N}}$ we have that:

$$
\mathbf{S}_{\mathbf{N}}=\left[\begin{array}{ccc}
0 & \frac{1}{2}\left(\sigma_{x y}-\sigma_{y x}\right) & \frac{1}{2}\left(\sigma_{x z}-\sigma_{z x}\right) \\
\frac{1}{2}\left(\sigma_{x y}-\sigma_{y x}\right) & 0 & \frac{1}{2}\left(\sigma_{y z}-\sigma_{z y}\right) \\
\frac{1}{2}\left(\sigma_{x z}-\sigma_{z x}\right) & \frac{1}{2}\left(\sigma_{z y}-\sigma_{y z}\right) & 0
\end{array}\right] .
$$

Similarly, applying the symmetry property, the state $\mathbf{S}_{\mathbf{N}}$ simplifies to:

$$
\mathbf{S}_{\mathbf{N}}=\left[\begin{array}{ccc}
\sigma_{x x}-P_{H} & \sigma_{x y} & \sigma_{x z} \\
\sigma_{y x} & \sigma_{y y}-P_{H} & \sigma_{x z} \\
\sigma_{z x} & \sigma_{z x} & \sigma_{z z}-P_{H}
\end{array}\right] .
$$

called the deviatory state for the diagonal elements (normal stresses), where the hydrostatic state is subtracted to remain the nonhydrostatic state. 

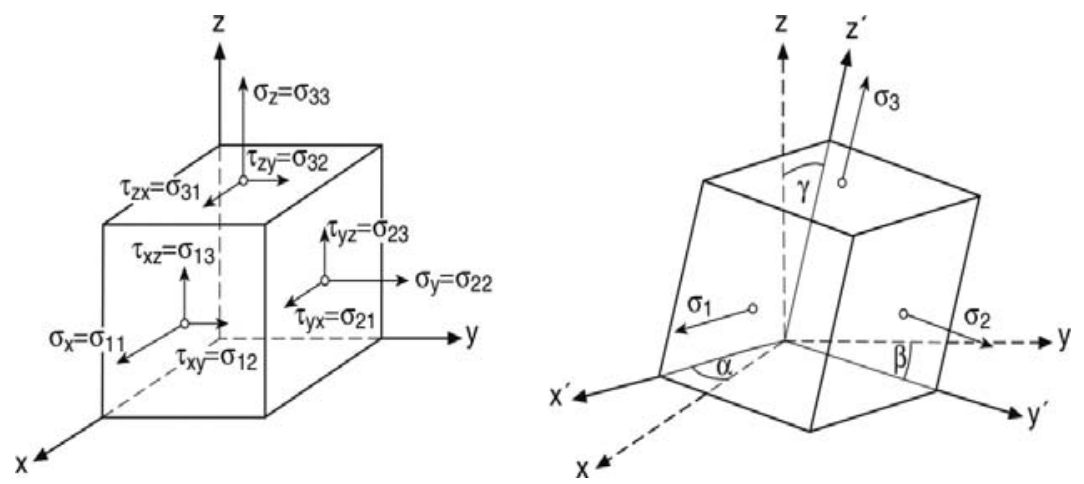

Figure 1 - A physical particle, and the stress field representation, $\sigma_{i j}$, where $\tau_{i, j}$ stands for the tangential components of $\sigma_{i j}$. The letters $(\alpha, \beta, \gamma)$ are the rotation angles for the $\left(z^{\prime}, y^{\prime}, z^{\prime}\right)$ with respect to the $(x, y, z)$ system. The particle is referenced to the point $Q$ located at the origin of the Cartesian system.

From the above discussion, we posed physically the stress field representations by the hydrostatic pressure state (6), and by the deviatory state (9). But, still other representations are possible as seen in the sequel, and all of them must be adapted here for analyzing the 2D case. The simple word "pressure" (positive or negative) is here always related to the normal stresses.

\section{Isotropic Media}

For an isotropic media, perfect linear elastic, the relation between stress and strain is given by Hooke's law in the simpler form:

$$
\sigma_{i j}=\lambda \theta \delta_{i j}+2 \mu \epsilon_{i j}
$$

where $\lambda$ and $\mu$ are the Lamé's elastic parameters, and $\delta_{i j}$ Kronecker's delta $\left(\delta_{i j}=0\right.$, if $i \neq j$ and $\delta_{i j}=1$, if $i=j$ ). The dimensionless $\theta$ parameter represents the dilatation given by the divergence of the displacement vector $\vec{u}$ as:

$$
\theta=\nabla \cdot \vec{u}=\frac{\partial u_{x}}{\partial x}+\frac{\partial u_{y}}{\partial y}+\frac{\partial u_{z}}{\partial z}
$$

The dimensionless strain tensor components $\epsilon_{i j}$ are defined in terms of the displacement components $u_{i}$ as:

$$
\epsilon_{i j}=\frac{1}{2}\left(\frac{\partial u_{i}}{\partial x_{j}}+\frac{\partial u_{j}}{\partial x_{i}}\right) .
$$

Also, the shear-extensional linear process produces a rotation tensor that is given by:

$$
\varphi_{i j}=\frac{1}{2}\left(\frac{\partial u_{i}}{\partial x_{j}}-\frac{\partial u_{j}}{\partial x_{i}}\right) .
$$

Therefore, once we know the displacement vector components $\left(u_{i}\right)$, the functionals quantities in Eqs. (10), (11), (12) and (13) can be calculated (Lowrie, 2011).
From the above discussion, for an isotropic media only two constants are necessary to completely specify the stress-strain relation. Boundary conditions are usually described by stress and strain relations (mixed boundary problem) across an interface, for continuity, free condition, and discontinuity. To be specific as an example, a discontinuity condition would be the case for a boundary along the a reservoir, with a geometrical form of an anticline, or of a stratigraphic trap.

We take in consideration only the constitutive parameters (density, Lamé's parameters); that means, the model does not take into account the separate structure contributions (like porosity, specific surface area, fluids, etc) for changes in the velocities and density distributions.

Since the model is related to the wave propagation in a perfect linear elastic medium, the elasto-dynamic equations of motion are given by:

$$
\left\{\begin{array}{l}
\frac{\partial \sigma_{x x}}{\partial x}+\frac{\partial \sigma_{x y}}{\partial y}+\frac{\partial \sigma_{x z}}{\partial z}=\rho \frac{\partial^{2} u_{x}}{\partial t^{2}} \\
\frac{\partial \sigma_{y x}}{\partial x}+\frac{\partial \sigma_{y y}}{\partial y}+\frac{\partial \sigma_{y z}}{\partial z}=\rho \frac{\partial^{2} u_{y}}{\partial t^{2}} \\
\frac{\partial \sigma_{z x}}{\partial x}+\frac{\partial \sigma_{z y}}{\partial y}+\frac{\partial \sigma_{z z}}{\partial z}=\rho \frac{\partial^{2} u_{z}}{\partial t^{2}} .
\end{array}\right.
$$

resumed to the form,

$$
\begin{aligned}
\frac{\partial \sigma_{i j}}{\partial x_{j}}=\rho \frac{\partial^{2} u_{i}}{\partial t^{2}}, & (i, j=1,2,3) ; \quad \text { or } \\
& (i, j=x, y, z) .
\end{aligned}
$$

That means that the spatial stress variation is related to the inertial force per unit volume, and without internal forces (the gravity effect). 
The velocities of the basic seismic body waves $(P$ and $S$ ) in homogeneous, isotropic, elastic media are given by:

$$
\begin{aligned}
& v_{\mathrm{P}}=\sqrt{\frac{K+\frac{4}{3} \mu}{\rho}}=\sqrt{\frac{\lambda+2 \mu}{\rho}}, \\
& v_{\mathrm{S}}=\sqrt{\frac{\mu}{\rho}},
\end{aligned}
$$

where $K$ is the bulk modulus (the modulus of incompressibility), $\mu$ is the shear modulus (modulus of rigidity), $\rho$ is the density of the material through which the wave propagates, and $\lambda$ is related to $K$ and $\mu$. From the above relations (16), the shear module is calculated by $\mu=v_{\mathrm{s}}^{2} \rho$, the lambda module by $\lambda=v_{\mathrm{p}}^{2} \rho-2 \mu$, and the gamma ratio by $\gamma=\frac{v_{\mathrm{S}}}{v_{\mathrm{p}}}$.

The density is usually a parameter admitted to change slowly with depth, from the surface to the top of the target interface; but, in some geological situations the density discontinuity can be rather severe. In the present case the density varies with $\rho=\rho(x, z)$, and is integrated over the calculating grid.

Now we turn to the differential equation system to be integrated, and that represents the problem's description for the static system, where the time variation is null. In this case, the equations are given by:

$$
\left\{\begin{array}{l}
\frac{\partial \sigma_{x x}}{\partial x}+\frac{\partial \sigma_{x y}}{\partial y}+\frac{\partial \sigma_{x z}}{\partial z}=0 \\
\frac{\partial \sigma_{y x}}{\partial x}+\frac{\partial \sigma_{y y}}{\partial y}+\frac{\partial \sigma_{y z}}{\partial z}=0 \\
\frac{\partial \sigma_{z x}}{\partial x}+\frac{\partial \sigma_{z y}}{\partial y}+\frac{\partial \sigma_{z z}}{\partial z}=\rho g
\end{array}\right.
$$

and resumed to the form,

$$
\begin{aligned}
\frac{\partial \sigma_{i j}}{\partial x_{j}}=\rho g \delta_{3 j}, & (i, j=1,2,3) ; \quad \text { or } \\
& (i, j=x, y, z) .
\end{aligned}
$$

It means that the sum of horizontal stress variations are considered null, and the vertical component is given by the gravity load in terms of force per unit area $(\rho g)$. Therefore, lateral tectonic stress is not here taken into consideration. The quantities $\rho$ and $g$, in other case, can be considered as spatial functions; i.e., $\rho=\rho(x, y, z)$ and $g=g(x, y, z)$.

We consider at first a simple model formed by a horizontally layered medium. The equation of equilibrium for the linear elastic medium for every single layer is given by:

$$
\frac{\partial \sigma_{i k}}{\partial x_{k}}=\rho g_{i},
$$

where $\sigma_{i k}$ are the components of stress tensor, $\rho$ is the rock density, and $g_{i}$ is the gravity acceleration. For the case of vertical gravity, $g_{i=z}(z) \approx g$, it is taken as constant for a rather short depth variation, and a simpler Eq. (19) is written in the following form:

$$
\frac{\partial \sigma_{z z}}{\partial x_{z}}=\rho g .
$$

The above equation has an elementary solution given by:

$$
\left.\sigma_{z z}\right|_{z=z_{0}}=\int_{z=0}^{z=z_{0}} \rho g d z=\rho g z_{0}=P_{0}\left(z_{0}\right),
$$

where $P_{0}=\rho g z_{0}$ is the weight of rocks per unit area; that is, the vertical pressure due to the overload at any depth $z_{0}$.

In the physical aspects of this description, it is not taken in consideration geological faulting and lithological diagenesis for the rock volume forming the reservoir (Nelson, 2001). Also, in another paper we deal with the case of bending of the geological formation resulting in an anticline structure (Sibiryakov et al., 2015).

\section{Scalar Pressure Field}

The pressure field present in the subsurface rocks is a main characteristic of the stress condition of the geological structures. Stress is nonhydrostatic even in horizontal layered media subject only to vertical gravity compactation without horizontal displacement. Lateral tectonic stress is, therefore, a condition to be explicitly considered in organizing the model.

For the present simplified model, the vertical stress, $\sigma_{z z}(z)$, is defined as equal to the weight of the overburden; i.e.:

$$
\sigma_{z z}=P_{z}=P_{0}(z) .
$$

The horizontal stress, $\sigma_{x x}(z)$, considering that $\sigma_{y y}=\sigma_{x x}$ in this case, is sufficiently lower than the vertical stress, $\sigma_{z z}$, and from Eqs. (17) and (21), it is shown to be given by:

$$
\sigma_{x x}=P_{x}=P_{0}\left(1-2 \gamma^{2}\right),
$$

where $P_{0}=P_{0}(z), \gamma=\gamma(z)=\frac{v_{\mathrm{S}}(z)}{v_{\mathrm{P}}(z)}$.

The scalar invariant hydrostatic pressure field, $P(z)=P_{H}$, was defined above as the average $P=P_{H}=\frac{1}{3}\left(\sigma_{x x}+\sigma_{y y}+\right.$ $\sigma_{z z}$ ). Using the generalized Hooke's law in the form (10), it is demonstrated that this field is given by:

$$
P=P_{H}=\left(\lambda+\frac{2}{3} \mu\right) \theta,
$$

where $\theta(z)$ is the dilatation given by $\mathrm{Eq} .(11)$, and $\lambda(z)$ and $\mu(z)$ are the already described Lamé's parameters. 
Another important physical characteristic is the overburden pressure discontinuity at layer boundaries $\left(\Delta P=P^{+}-P^{-}\right.$, at $z$, and $z$ positive downwards), that will exist if the velocity $\gamma$ ratio has a discontinuity. Considering the simplest case of layered media, and Hooke's law (10), it is demonstrated that the discontinuity $\Delta P$ is given by:

$$
\Delta P(z)=\frac{4}{3}\left(\gamma_{1}^{2}-\gamma_{2}^{2}\right) P_{0}(z),
$$

where $\gamma_{1}$ is the upper and $\gamma_{2}$ the lower layer parameters across the interface positioned at depth $z$. Therefore, the overburden pressure varies stepwise as positive or negative with depth, if the underlying $\gamma$ ratio is different from the overlying $\gamma$ ratio. This idea may appear rather strange in simple geological descriptions, but it is an important fact related to the nonelementary behavior of stress in solids, and at this point we can recall Heim's rule for lithostatic stress variation in the subsurface (Zang \& Stephansson, 2010), as depicted if Figure 2.

Continuing now with the intensity of tangential stress, which is a form to measure the mechanical instability responsible for the failure of the solid rock skeleton and fracturing. For the simple layered media, the scalar invariant tangential stress, $P_{T}(z)$, is defined by the average of the difference between horizontal and vertical stresses, and with the use of Hooke's law (10), we arrive at the result:

$$
P_{T}=\frac{1}{2}\left(\sigma_{z z}-\sigma_{x x}\right)=\gamma^{2} P_{z} .
$$

Again, it also depends on velocity $\gamma$ ratio.

For the computational experiments, where the data is of any origin, the vertical and horizontal numerical partial derivatives with respect to $x, y$ and $z$ are calculated using symmetrical forms (Abramowitz \& Stegun, 1970). For the first order derivatives along $x$ or $z$ as:

$$
\begin{gathered}
\frac{\partial}{\partial x} f_{0,0}= \\
\frac{1}{4 h}\left(f_{1,1}-f_{-1,1}+f_{1,-1}-f_{-1,-1}\right)+O\left(h^{2}\right) .
\end{gathered}
$$

And for the second order derivatives along $x$ and $z$ as:

$$
\begin{gathered}
\frac{\partial^{2}}{\partial x \partial z} f_{0,0}= \\
\frac{1}{4 h^{2}}\left(f_{1,1}-f_{-1,1}+f_{1,-1}-f_{-1,-1}\right)+O\left(h^{2}\right) .
\end{gathered}
$$

The main full application should be to predict 3D stress and strain around a geological reservoir volume, and to present the results in form of a data cube, from where vertical and horizontal sections can be extracted and interpreted. To be specific, here we have only produced vertical sections, and this means that the blocks have unitary thickness across the $y$ axis for the results to be in force per unit area.

In the next section we present one form of sensitivity analysis to measure qualitatively the decay of the resolution in the stress prediction, that depends on the smoothing of the input data. Another form of sensitivity analysis would take us to the domain of the differential components of stress-strain field in a feature work (Frank, 1978). And in the present example we stay close to the seismic migration methodologies.

\section{RESULTS}

The experiments were devided in two main parts based on the input data: Original and Smoothed input data $\left(v_{P}, v_{S}\right.$ and $\left.\rho\right)$. Among the several experiments, the selected results for presentation had symmetrical smoothing operators with the lengths of 41 , 81, and 101 points.

The same smoothing process (but could have been different) was equally applied to the input model components $\left(v_{P}, v_{S}\right.$ and $\rho$ ) to analyze the resolution decay of the prediction results. We focused on some reservoir targets, as the input parameters systematically deviate from the original (real) values, what follows the same criteria as used in the numerical tests for stack, inversion and migration experiments. For the smoothing process, we used the routine Smooth2a that is present in the SU (Cohen \& Stockwell, 2005) and Matlab (Schilling \& Harris, 2005) codes, and it represents an averaging symmetric rectangular operator, and for the borders, the operator is supplied with less points, as the central point of the rectangular operator reaches the end of the smoothing area (Reeves, 2009).

The data selected and used for the present test was from the Marmousi seismic project (Versteeg \& Grau, 1991), and described by Martin et al. (2006) as we show in Figure 3, where we call attention to the gas an oil reservoir targets. The Marmousi model has the compressional and shear wave velocities and density models that are shown in the figure sequence organized in Table 1 , together with impedance calculation.

Table 2 gives the sequence of figures of the calculated constitutive parameters based on the input data.

There are different categories of figures for presenting the subsurface stress field, and Table 3 lists the results for field magnitudes and ratios.

The simple Table 4 lists the figure that we put in evidence for the result of the vertical field discontinuity.

The double line of Table 5 shows the results for the field variations calculated by spatial derivatives. 
Table 1 - Input data and impedance.

\begin{tabular}{c|l}
\hline Figure & Description \\
\hline 4 & $v_{P}(x, z)$ velocity \\
5 & $v_{S}(x, z)$ velocity \\
6 & $\rho(x, z)$ density \\
7 & $I_{P}(x, z)=v_{P} \rho$, P wave impedance \\
8 & $I_{S}(x, z)=v_{S} \rho$, S wave impedance \\
9 & $\Delta I_{P S}(x, z)=I_{P}-I_{S}$, P-S waves impedance contrast \\
10 & $R_{P S}=\frac{I_{P}-I_{S}}{I_{P}+I_{S}}$, vertical normalized impedance contrast coefficient \\
\hline
\end{tabular}

Table 2 - Constitutive parameters.

\begin{tabular}{c|l}
\hline Figure & Description \\
\hline 11 & $\gamma(x, z)$, gamma ratio \\
12 & $\mu(x, z)$, shear module \\
13 & $\lambda(x, z)$, lambda module \\
14 & $\sigma(x, z)$, Poisson module \\
\hline
\end{tabular}

Table 3 - Pressure fields.

\begin{tabular}{c|l}
\hline Figure & Description \\
\hline 15 & $\sigma_{z z}=P_{z}$, vertical pressure \\
16 & $\sigma_{x x}=P_{x}$, horizontal pressure \\
17 & $P_{H}$, hydrostatic pressure field \\
18 & $P_{X H}=\sigma_{x x}-P_{H}$, horizontal deviatory hydrostatic pressure field \\
19 & $P_{Z H}=\sigma_{z z}-P_{H}$, vertical deviatory hydrostatic pressure field \\
20 & $P_{T}=\frac{1}{2}\left(\sigma_{z z}-\sigma_{x x}\right)$, tangential stress, as a deviatory pressure field \\
21 & $k_{x z}(x, z)$, dimensionless stress ratio, as a full section \\
22 & $k_{x z}=\frac{\sigma_{x x}}{\sigma_{z z}}$, dimensionless stress ratio, as depth profiles for details \\
\hline
\end{tabular}

Table 4 - Pressure field discontinuity.

\begin{tabular}{c|l}
\hline Figure & Description \\
\hline 23 & $\Delta P_{z}$, vertical pressure discontinuity across interfaces \\
\hline
\end{tabular}

Table 5 - Spatial derivatives.

\begin{tabular}{c|l}
\hline Figure & Description \\
\hline 24 & $\frac{\partial P_{z}}{\partial z}$, vertical variation of the vertical pressure field \\
25 & $\frac{\partial P_{x}}{\partial x}$, horizontal variation of the horizontal pressure field \\
\hline
\end{tabular}




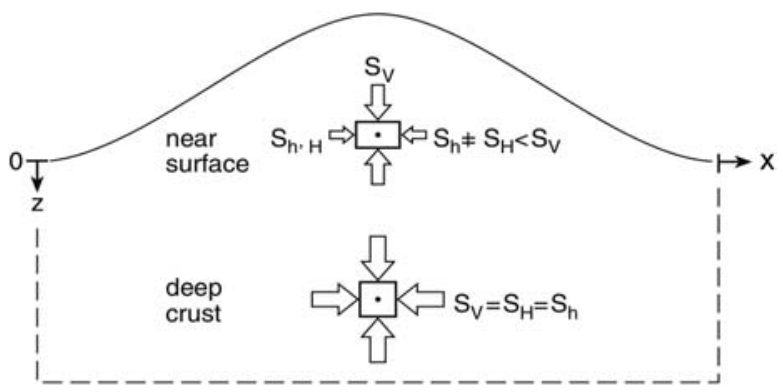

Figure 2 - Old geological concept known as Heim's rule for the stress variation in the crust. $S_{V}$ stands for the vertical stress, $S_{H}$ for the maximum horizontal stress, $S_{h}$ for the minimum horizontal stress, and where these quantities equalize as depth increases. This figure was redrawn based on Zang \& Stephansson (2010).

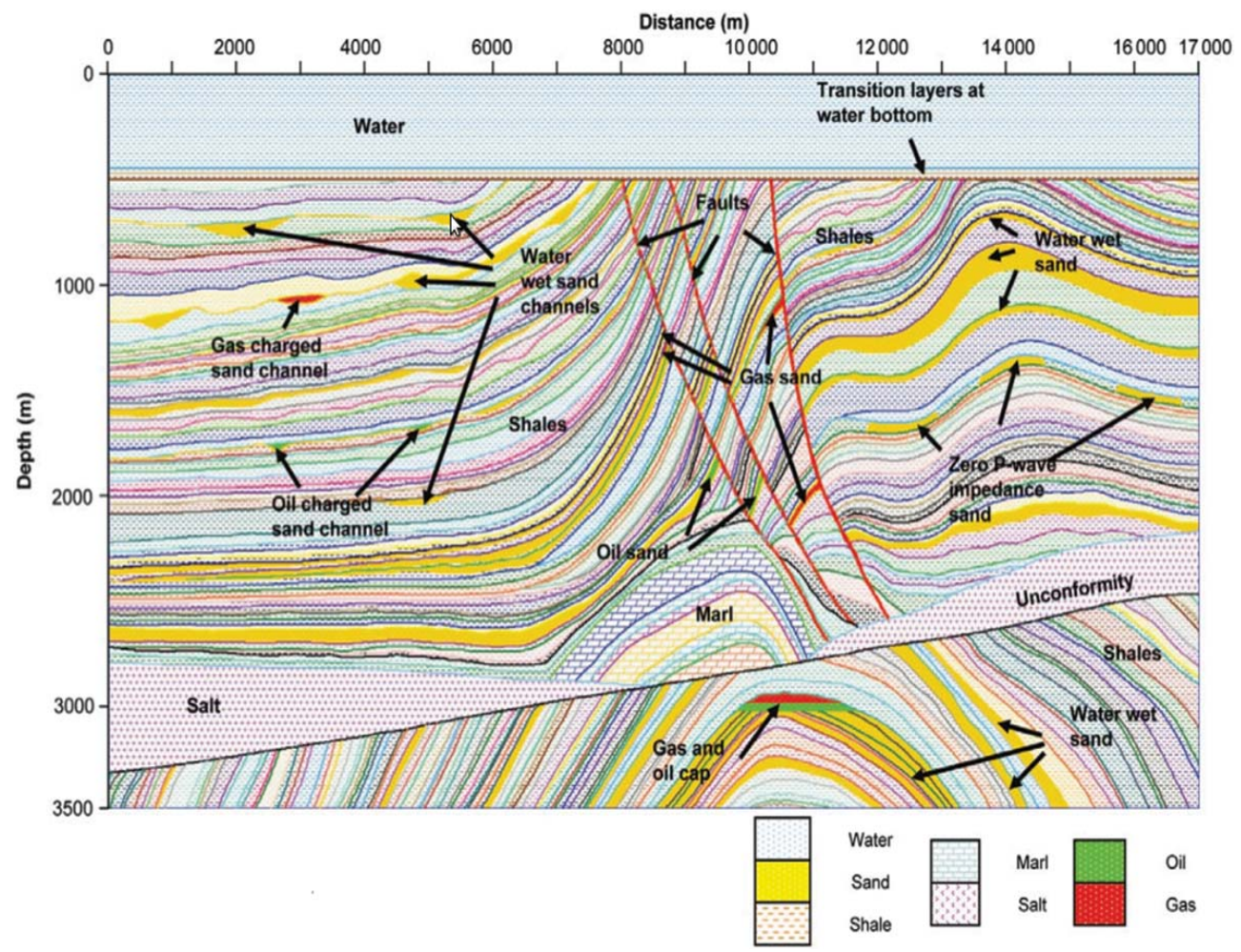

Figure 3 - Geological description of the Marmousi according to Martin et al. (2006) with the oil and gas reservoir targets pointed to. We underlined the target in the bottom sequence related to the classical anticline structure.

Based on theorectical aspects, different figures can be constructed as criteria for the analysis of the subsurface stress and pressure conditions. Here, we present some selected figures to focus at details and correlation with the low pressure areas below specific interfaces pointed as potential fluid accumulation zones.

It should be clear that the analysis is basically lithostratigraphical, and that we are not concerned with chronological concepts; even though, the smoothing process, that eliminates the high frequency content in the input data, can suggest a chronolog- ical and stratigraphical analysis, that is more complex and needs more constraints.

Figures 4, 5 and 6 show the input $v_{P}, v_{S}$ and $\rho$ data, where the main aspects (low frequency) are still recognized, but the details (high frequency) have been very much attenuated with the smoothing process. Figures 7 and 8 show the impedances for the $P$ and $S$ waves.

As we look for contrast informations to be able to point out the presence of a reservoir, Figure 9 show the P-S impedance 


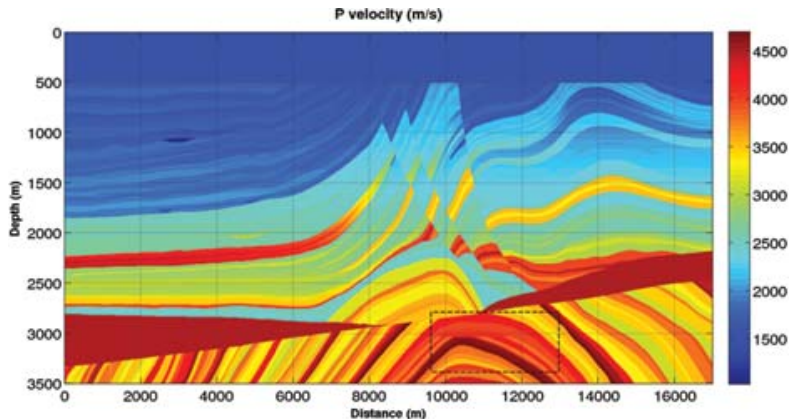

(a) Original model

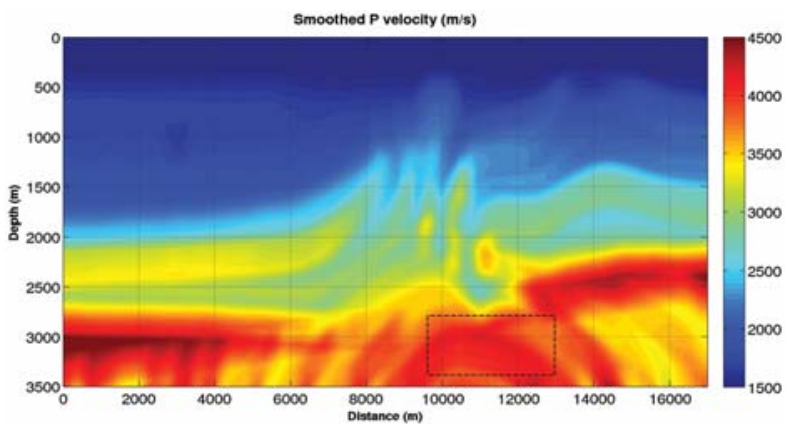

(c) Smoothing with 81 points.

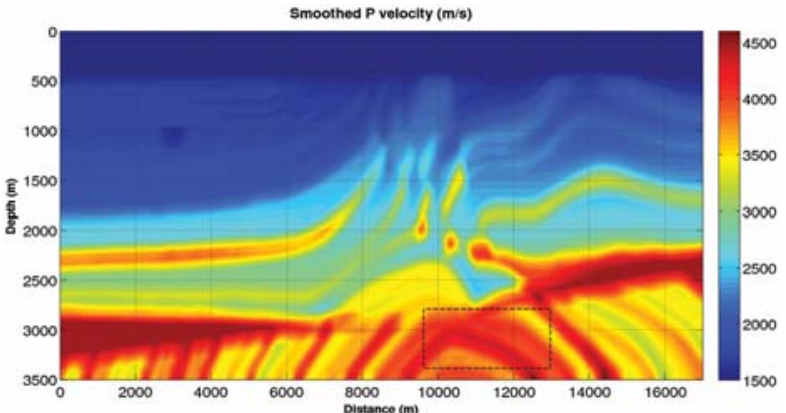

(b) Smoothing with 41 points.

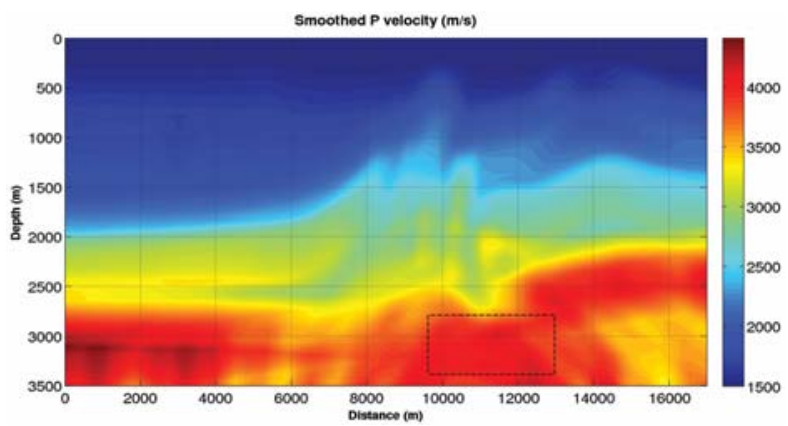

(d) Smoothing with 121 points.

Figure 4 - Velocity, $v_{\mathrm{P}}(x, z)$.

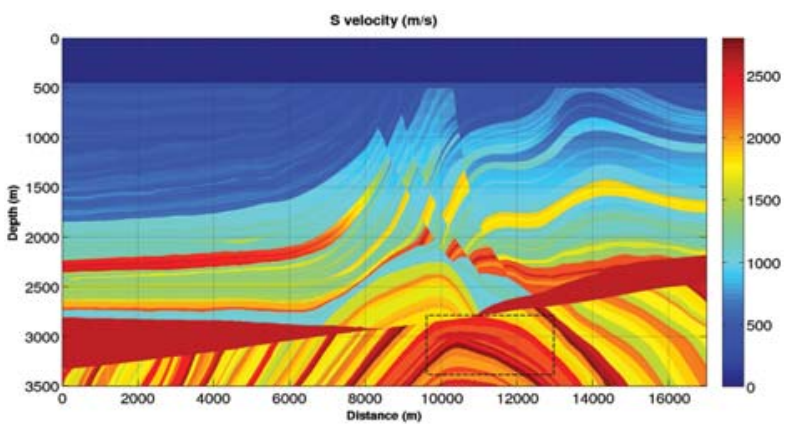

(a) Original model.

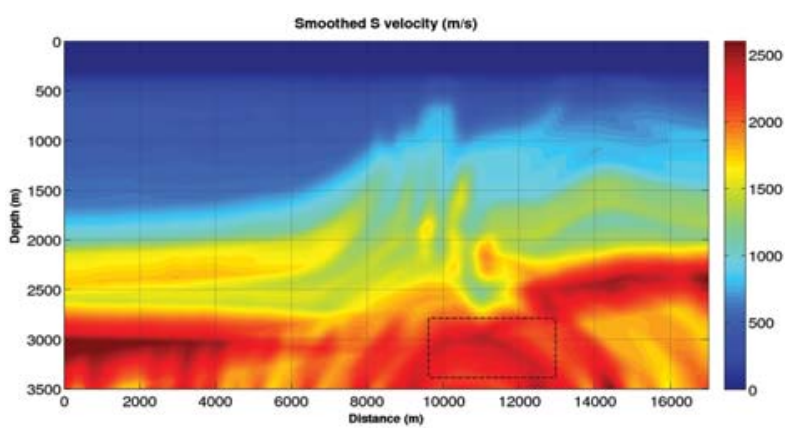

(c) Smoothing with 81 points.

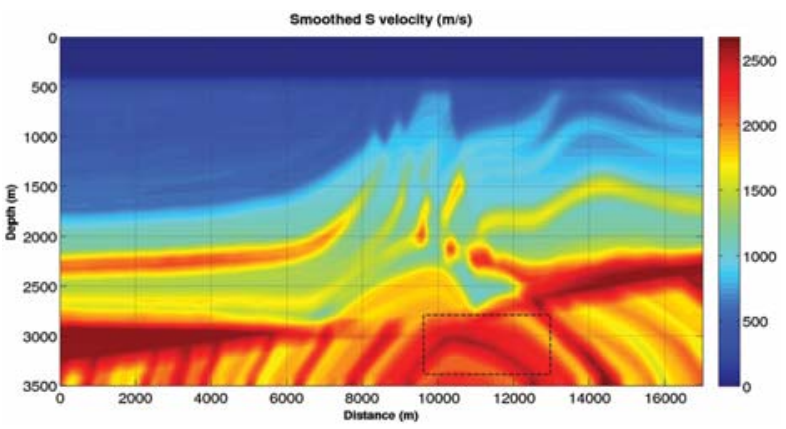

(b) Smoothing with 41 points.

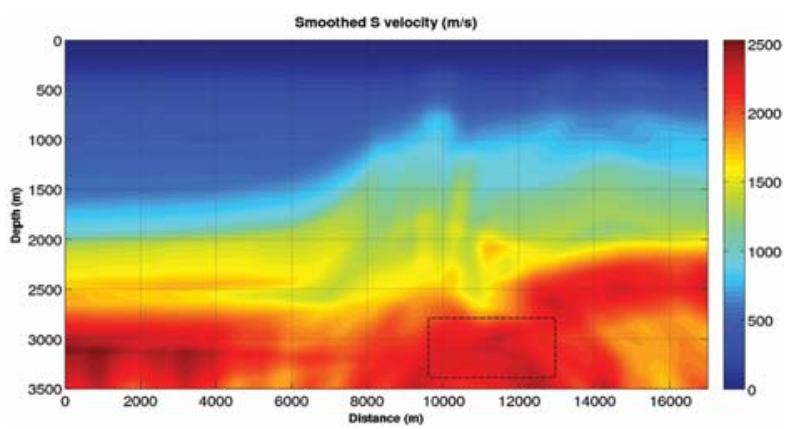

(d) Smoothing with 121 points.

Figure 5 - Velocity, $v_{\S}(x, z)$. 


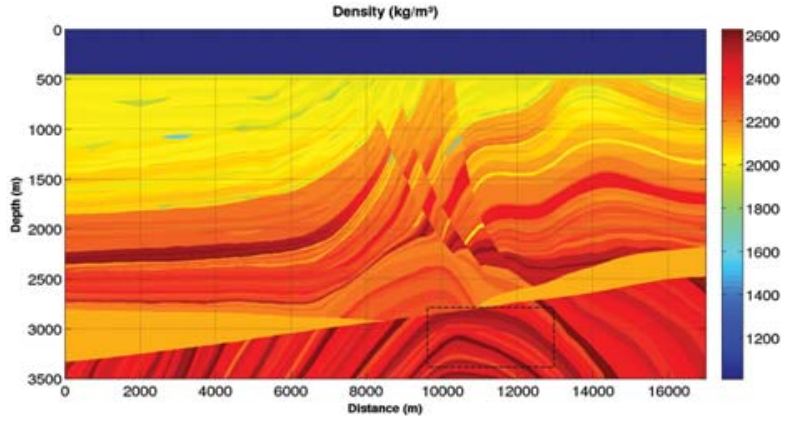

(a) Original model.

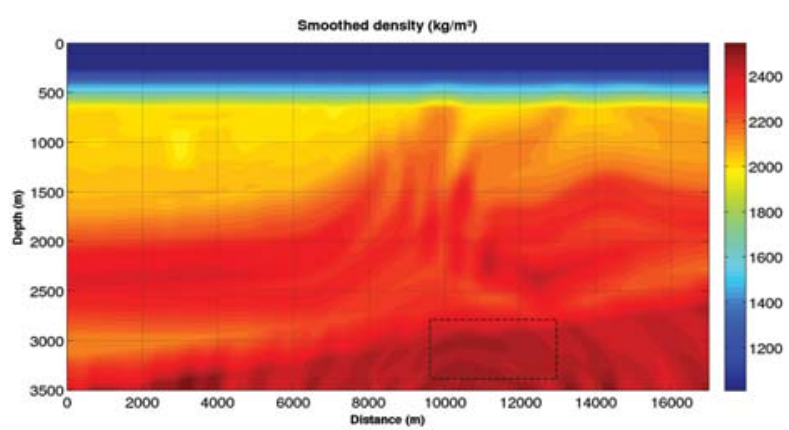

(c) Smoothing with 81 points.

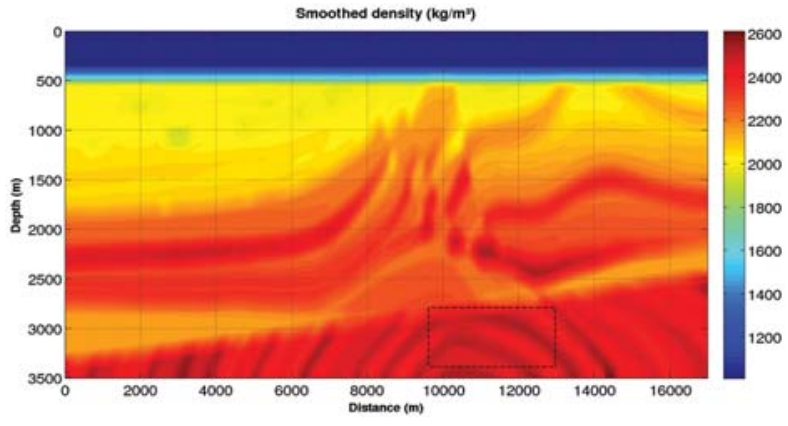

(b) Smoothing with 41 points.

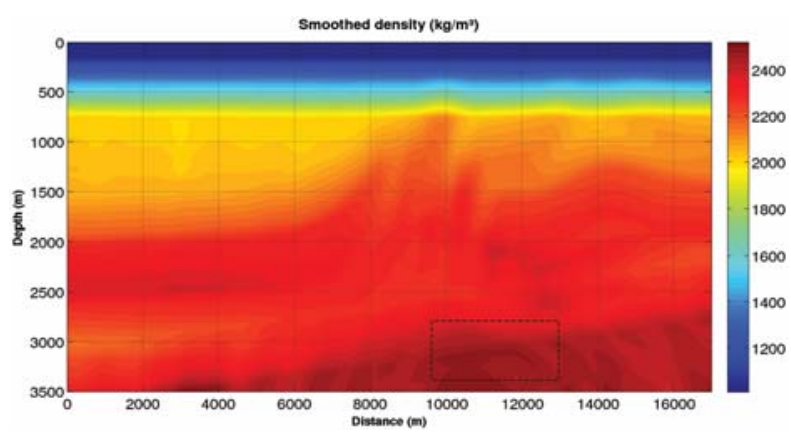

(d) Smoothing with 121 points.

Figure 6 - Density, $\rho(x, z)$.

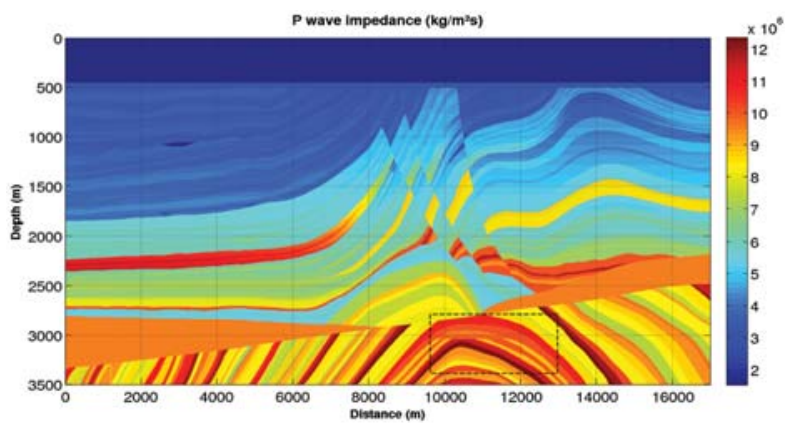

(a) Original model.

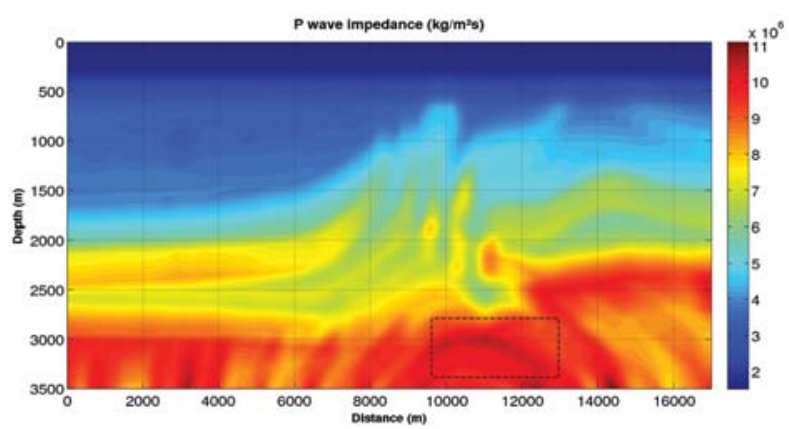

(c) Smoothing with 81 points.

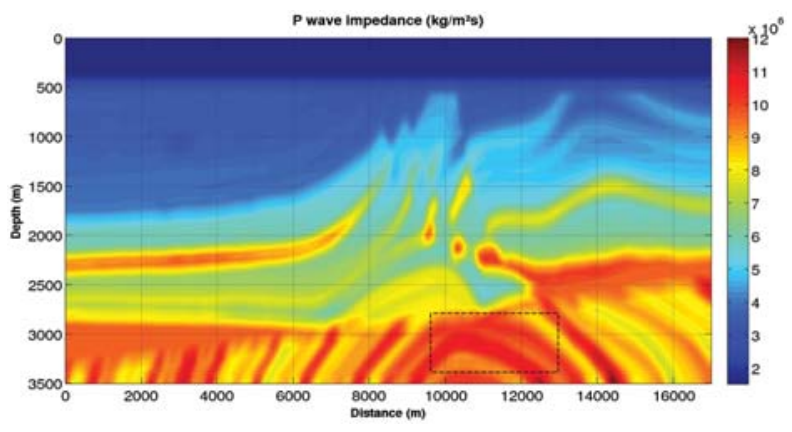

(b) Smoothing with 41 points.

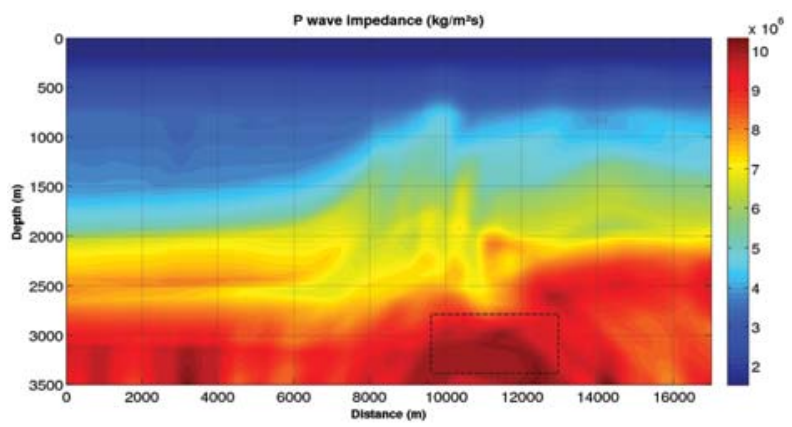

(d) Smoothing with 121 points.

Figure 7 - $\mathrm{P}$ wave impedance, $I_{\mathrm{P}}(x, z)$. 


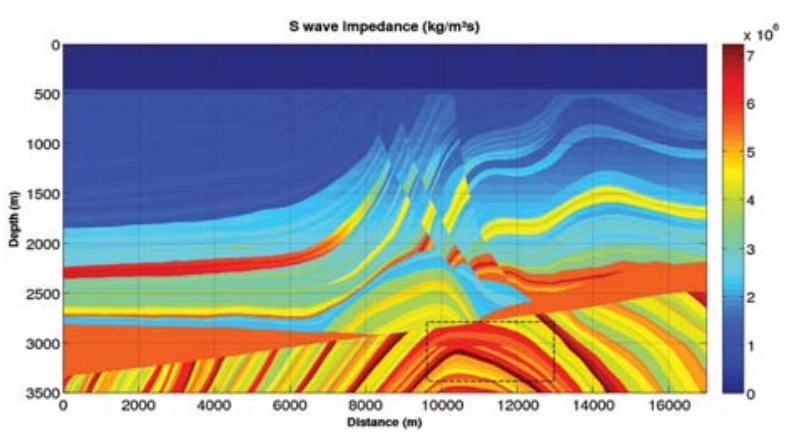

(a) Original model.

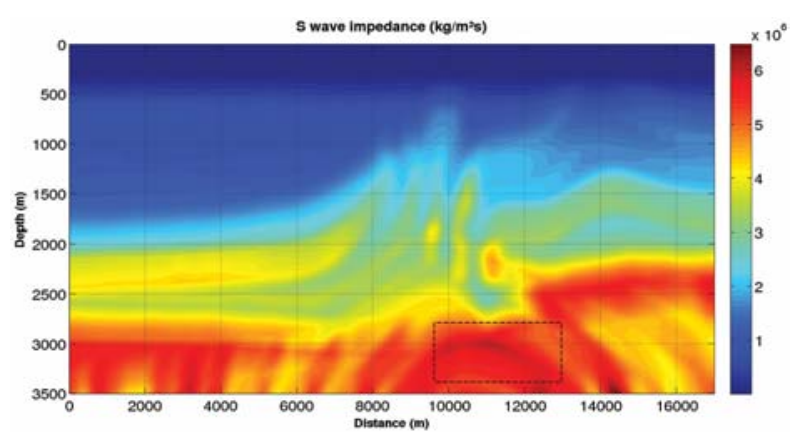

(c) Smoothing with 81 points.

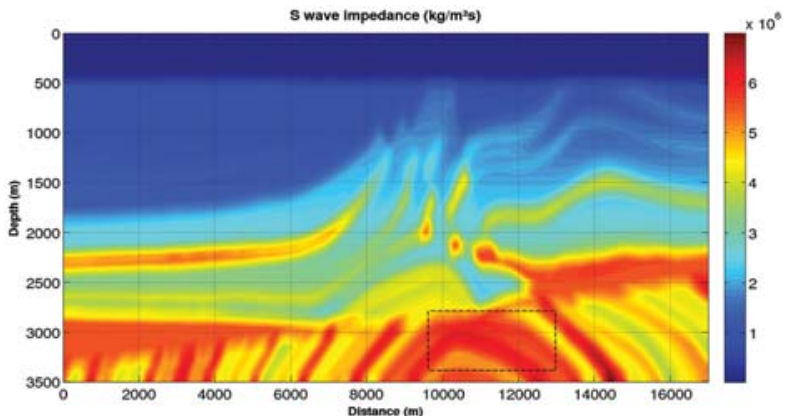

(b) Smoothing with 41 points.

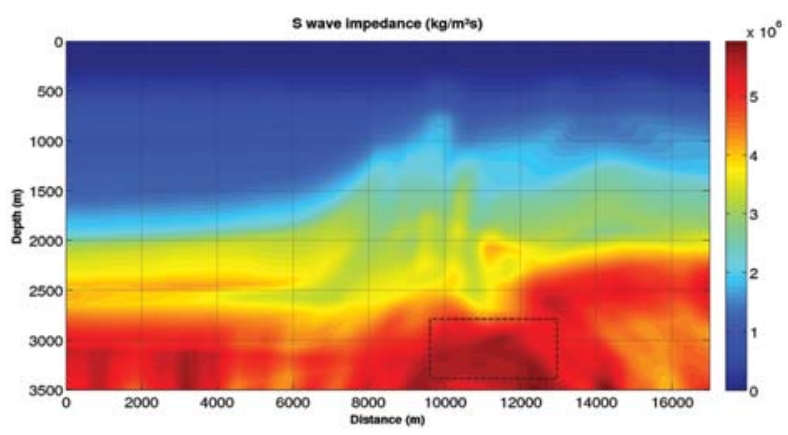

(d) Smoothing with 121 points.

Figure 8 - $\mathrm{S}$ wave impedance, $I_{\mathrm{S}}(x, z)$.

contrast, Figure 10 the normalized vertical impedance contrast coefficient between $\mathrm{P}$ and $\mathrm{S}$ waves defined as $R_{P S}=\frac{I_{P}-I_{S}}{I_{P}+I_{S}}$. Figure 9 keeps a good correlation with 23, and Figure 10 with Figure 21 , characterized by a linear oscillatory increasing behavior.

Figures $11,12,13$ and 14 show the $\gamma, \mu$ and $\lambda$ parameters calculated directly from the correspondent $v_{P}, v_{S}$ and $\rho$ data. These figures also show similar characteristics, where the main aspects (low frequency content) are still recognized, but the details (high frequency content) have been attenuated. The Poisson ratio, $\sigma=\frac{1-2 \gamma^{2}}{2-2 \gamma^{2}}$, in Figure 14, presents only positive values between 0.3 and 0.5 .

One goal, based on description for this model by Versteeg \& Grau (1991), is marked with a rectangular window defined along the $x$-axis with the coordinates of $10.000-11.000$ meters, and in the $z$-axis by the coordinates of $2.800-3.200$ meters. That is, the top of the anticline defined as an oil and gas reservoir. Therefore, this spatial window marks a confined low pressure zone representing the reservoir.

Figure 15 shows the vertical pressure field calculated by Eq. (22), and it displays a direct visual difficulty to identify reservoir structures as the smoothing increases. Figure 16 shows the horizontal pressure field calculated by Eq. (23). This figure clearly still shows details of the target reservoir and of the geological structure as the smoothing increases, and it becomes one main conclusion of this study.

Figure 17 shows the hydrostatic pressure field calculated by Eq. (6) adapted to the 2D case as $P=P_{H}=\frac{1}{2}\left(\sigma_{x x}+\sigma_{z z}\right)$, and it does not show details of the target reservoir in the geological structure as the smoothing increases, but a very smooth field expression. Figure 18 shows the horizontal deviatory hydrostatic pressure field, $P_{X H}=\sigma_{x x}-P_{H}$. Figure 19 shows the vertical deviatory hydrostatic pressure field, $P_{Z H}=\sigma_{z z}-P_{H}$. Figure 20 shows the deviatory tangential pressure field (average of the difference between the horizontal and vertical stress fields calculated by Eq. (26)). This result is built from the results in Figures 15 and 16, and it also does not show details of the target in the geological structure as the smoothing process increases.

Figure 21 shows the stress dimensionless ratio section (ratio between the horizontal and vertical stress fields calculated by Eqs. (23) and (22)), and it does not show details of the target in the geological structure, but rather a consistent linear behavior of $k_{x z}$ with $z$ as the smoothing process increases.

To make the section in Figure 21 more visible, Figure 22 shows the stress dimensionless ratio depth profiles, $k_{x z}(z)$, for 


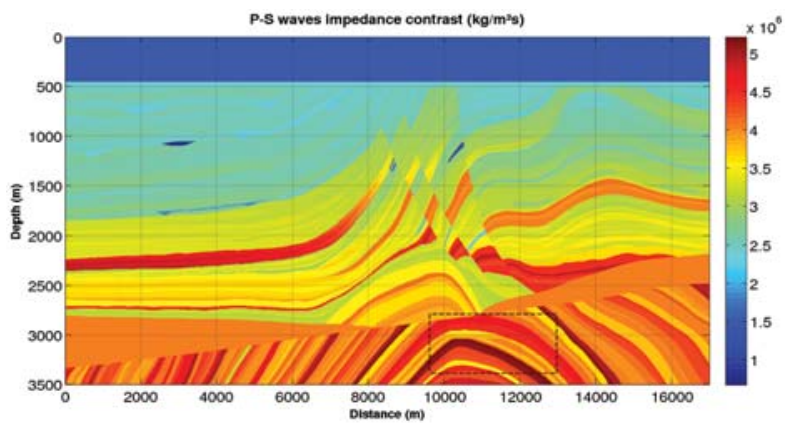

(a) Original model.

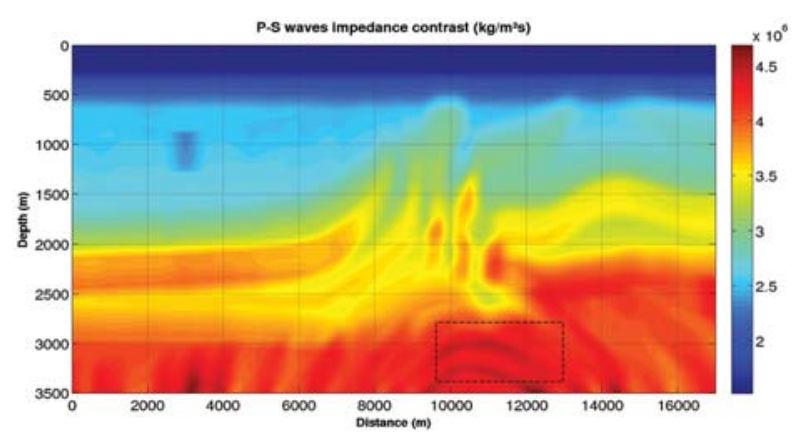

(c) Smoothing with 81 points.

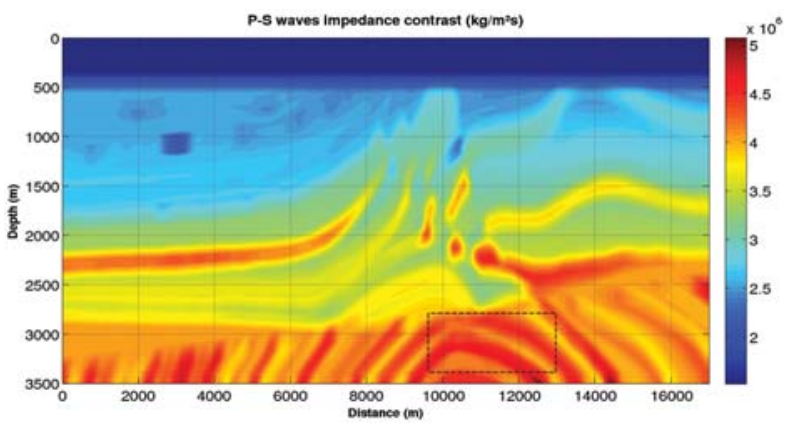

(b) Smoothing with 41 points.

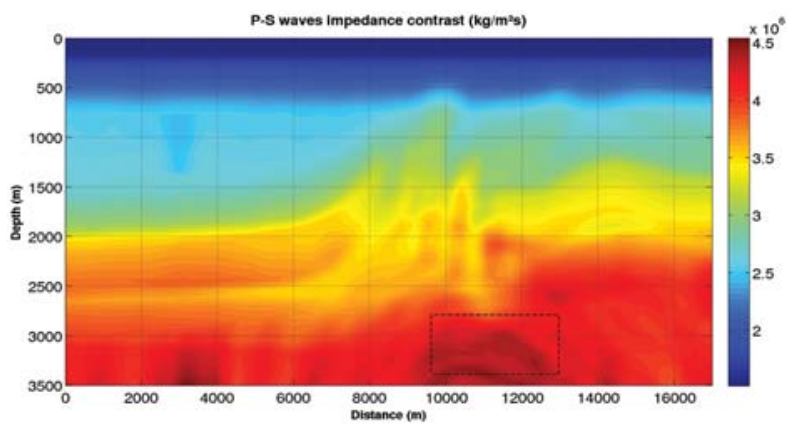

(d) Smoothing with 121 points.

Figure 9 - P-S wave impedance contrast, $\Delta I_{\mathrm{PS}}(x, z)$.

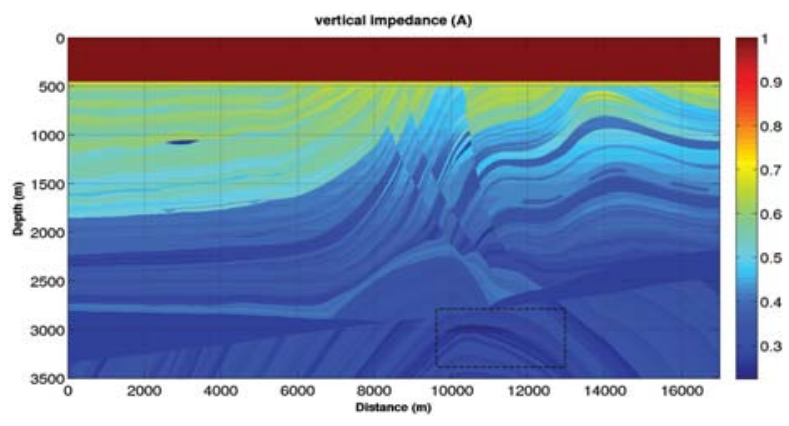

(a) Original model.

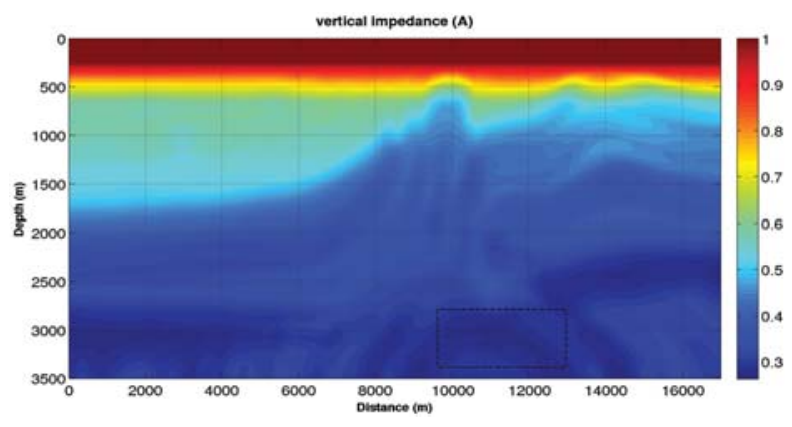

(c) Smoothing with 81 points.

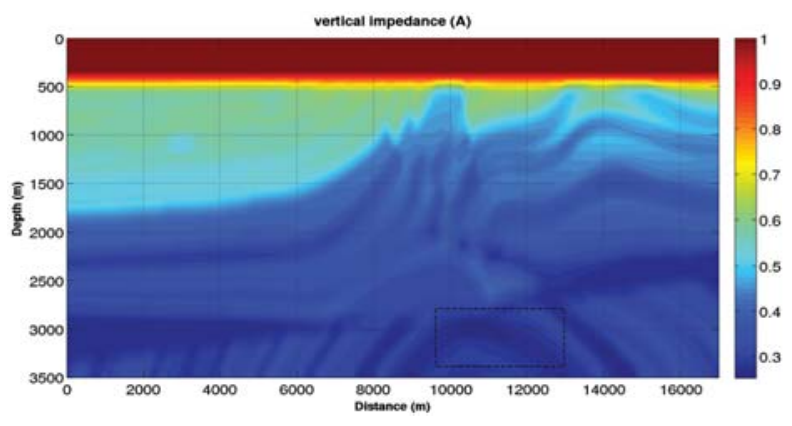

(b) Smoothing with 41 points.

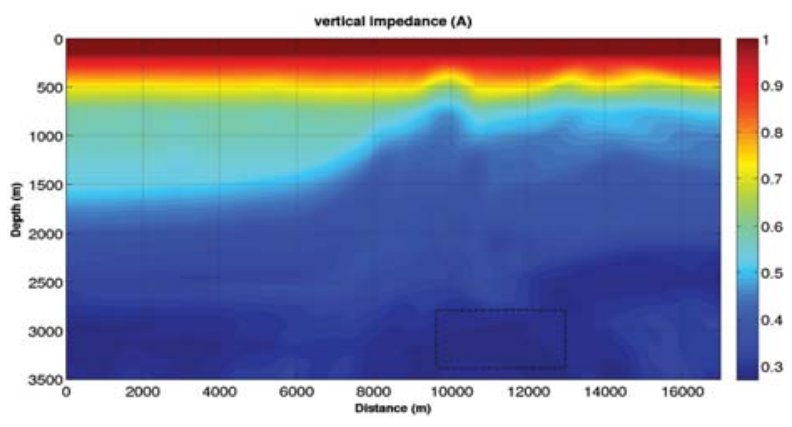

(d) Smoothing with 121 points.

Figure 10 - Normalized nondimensional, $(A)$, vertical impedance coefficient contrast, $R_{\mathrm{PS}}(x, z)=\frac{I_{P}-I_{S}}{I_{P}+I_{S}}$. 


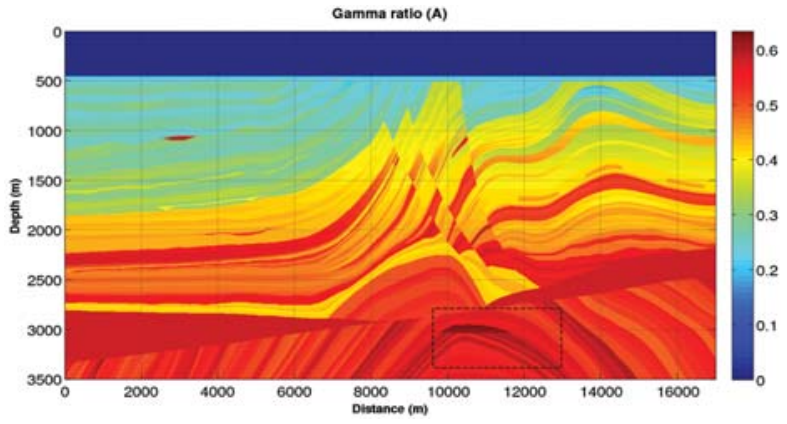

(a) Original model.

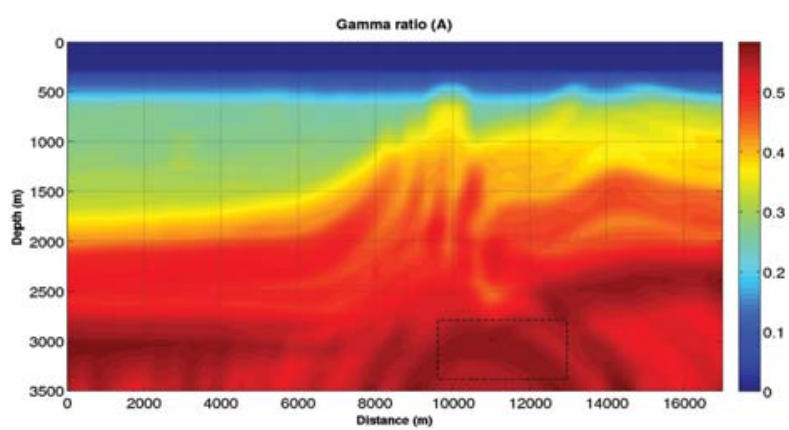

(c) Smoothing with 81 points.

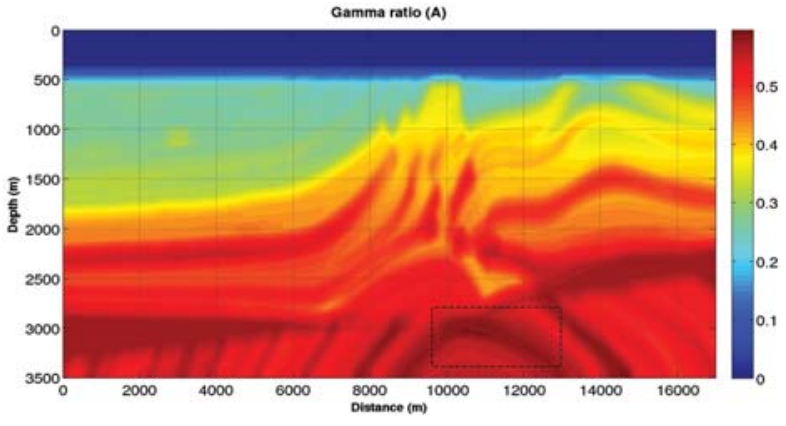

(b) Smoothing with 41 points.

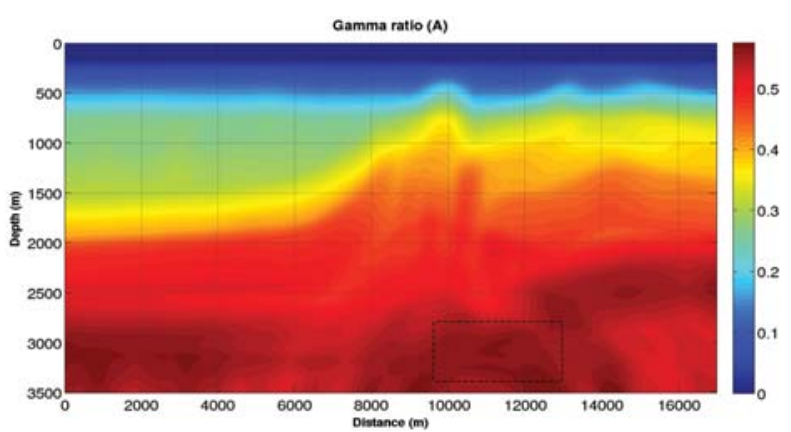

(d) Smoothing with 121 points.

Figure 11 - Gamma, $\gamma(x, z)$.

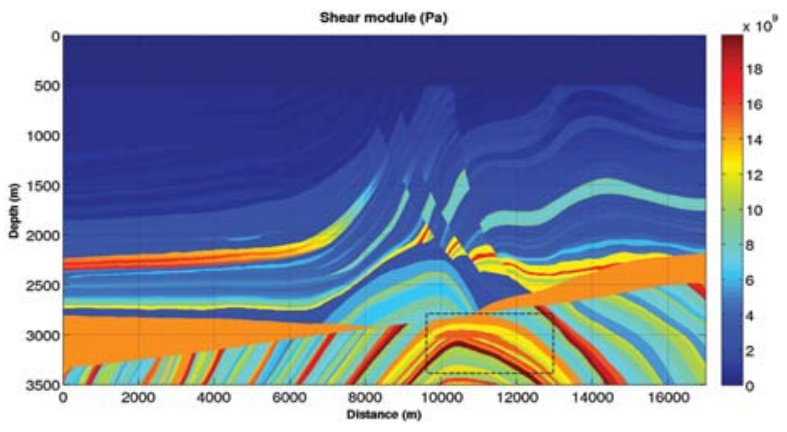

(a) Original model.

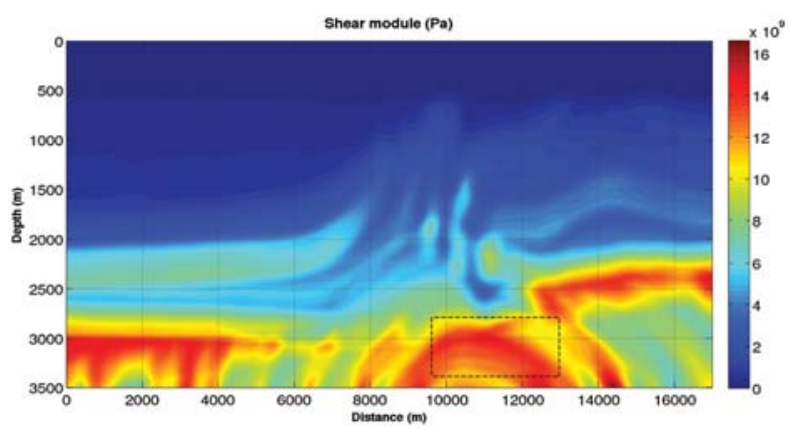

(c) Smoothing with 81 points.

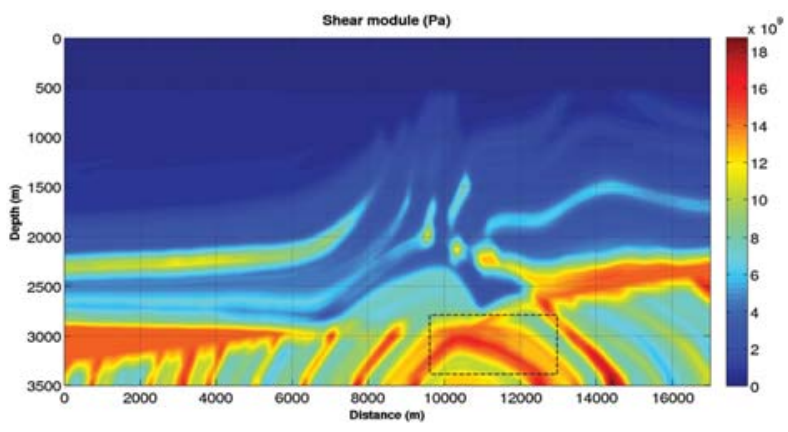

(b) Smoothing with 41 points.

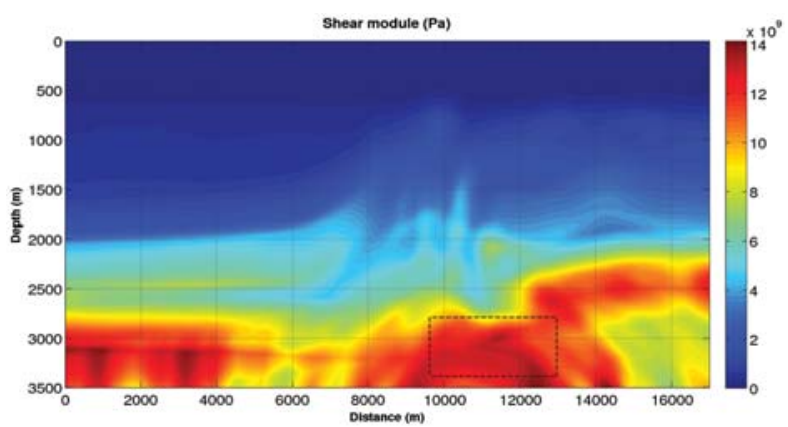

(d) Smoothing with 121 points.

Figure $12-\mathrm{Mu}, \mu(x, z)$. 


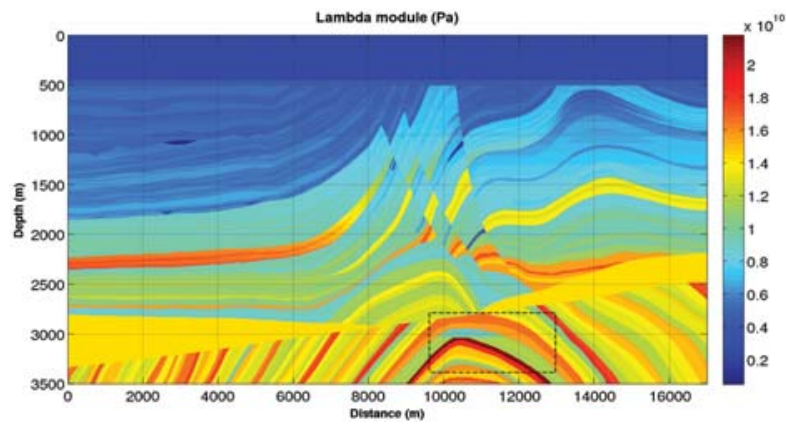

(a) Original model.

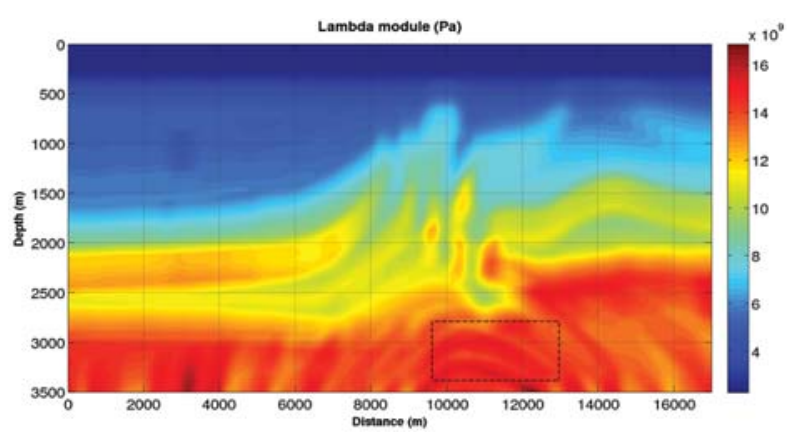

(c) Smoothing with 81 points.

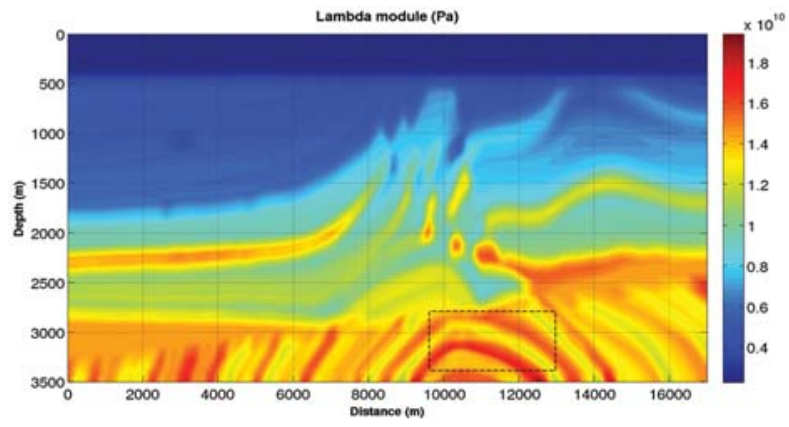

(b) Smoothing with 41 points.

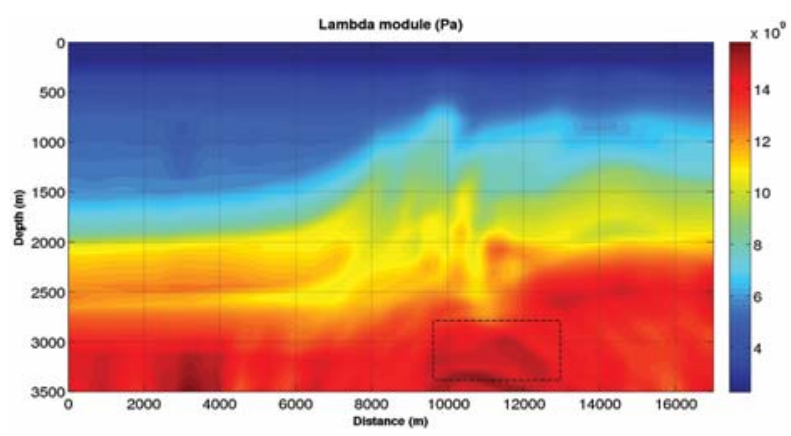

(d) Smoothing with 121 points.

Figure 13 - Lambda, $\lambda(x, z)$.

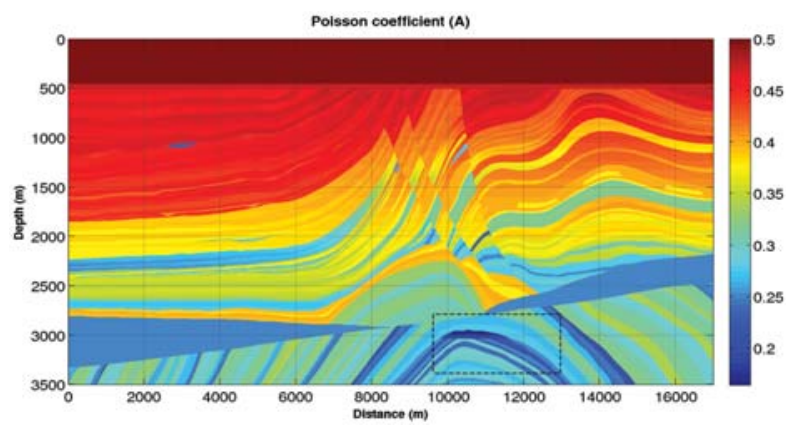

(a) Original model.

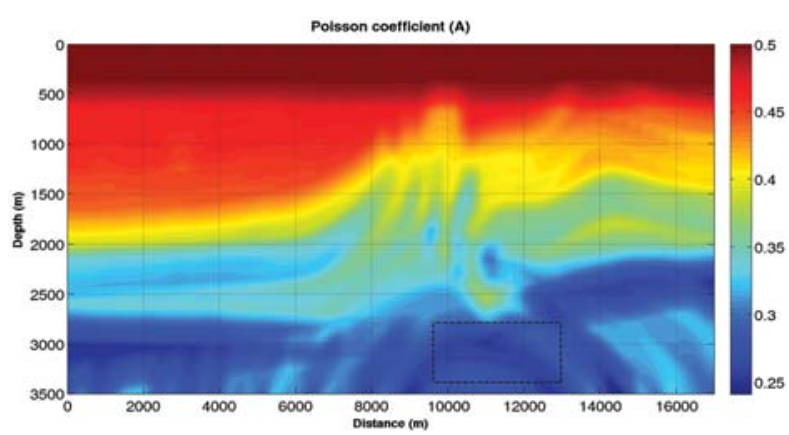

(c) Smoothing with 81 points.

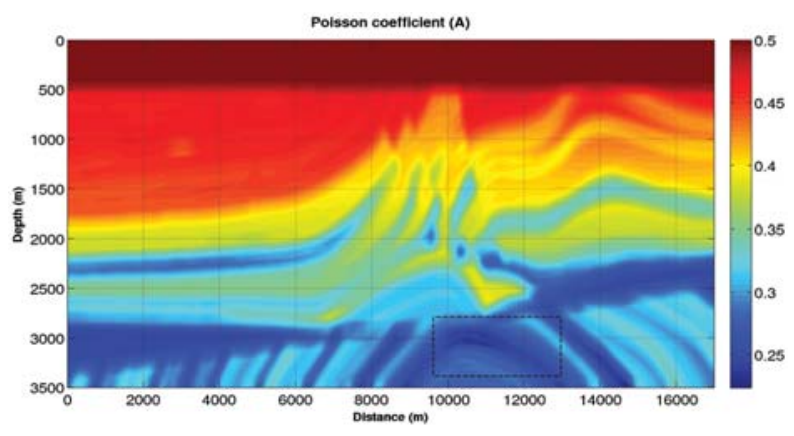

(b) Smoothing with 41 points.

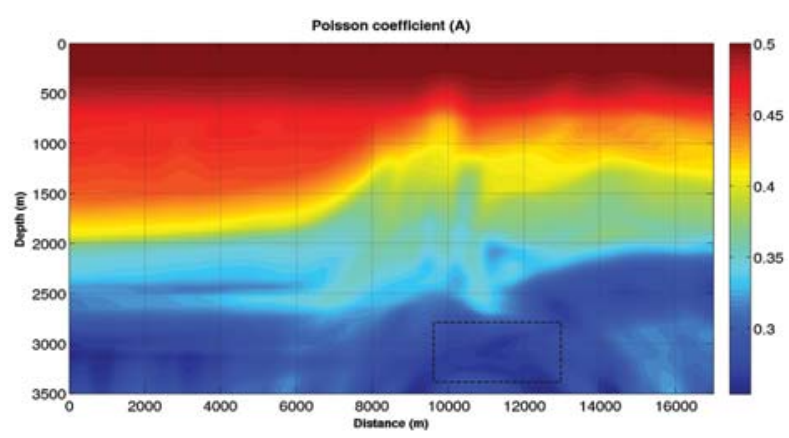

(d) Smoothing with 121 points.

Figure 14 - Poisson, $\sigma(x, z)$. 


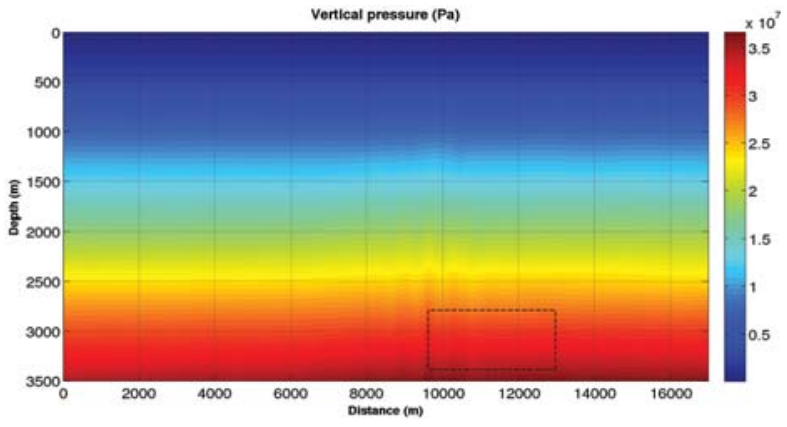

(a) Original model.

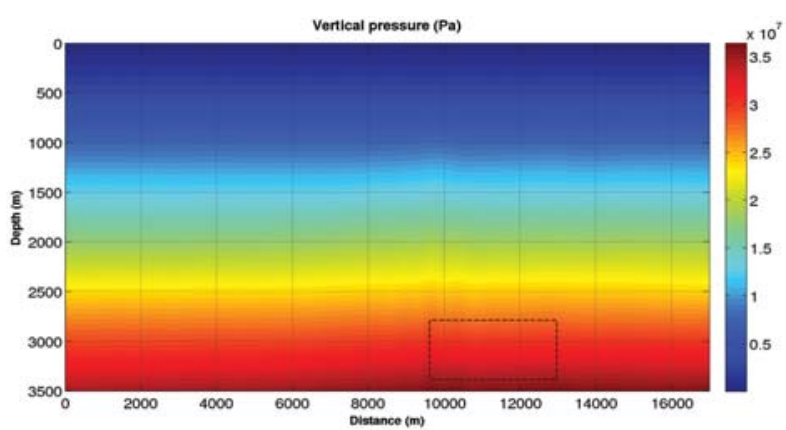

(c) Smoothing with 81 points.

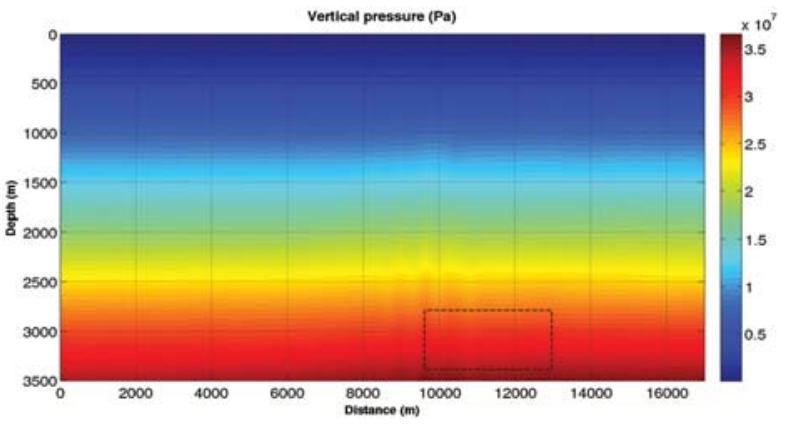

(b) Smoothing with 41 points.

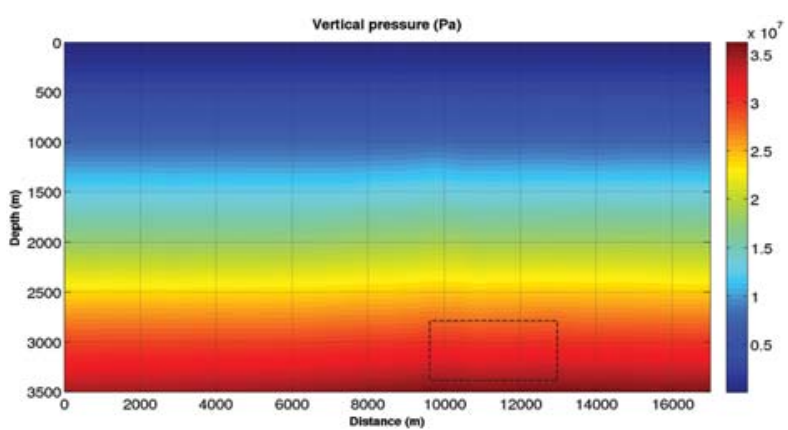

(d) Smoothing with 121 points.

Figure 15 - Vertical pressure field, $P_{z}(x, z)$.

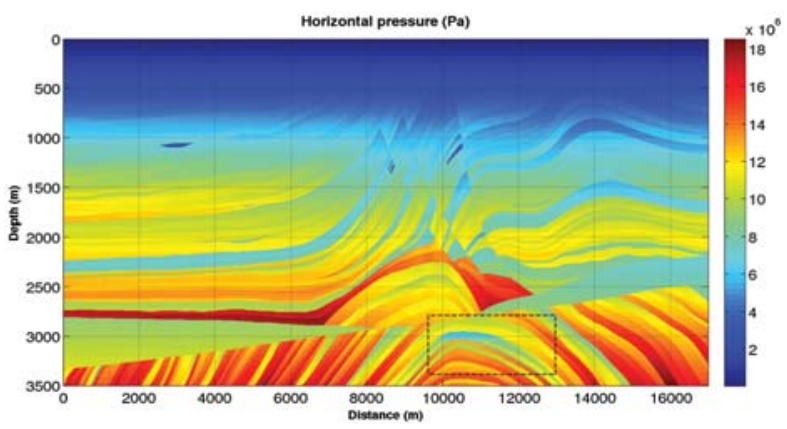

(a) Original model.

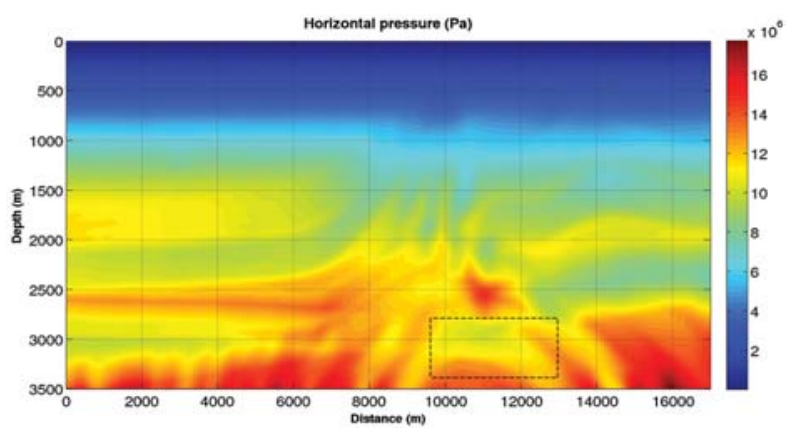

(c) Smoothing with 81 points.

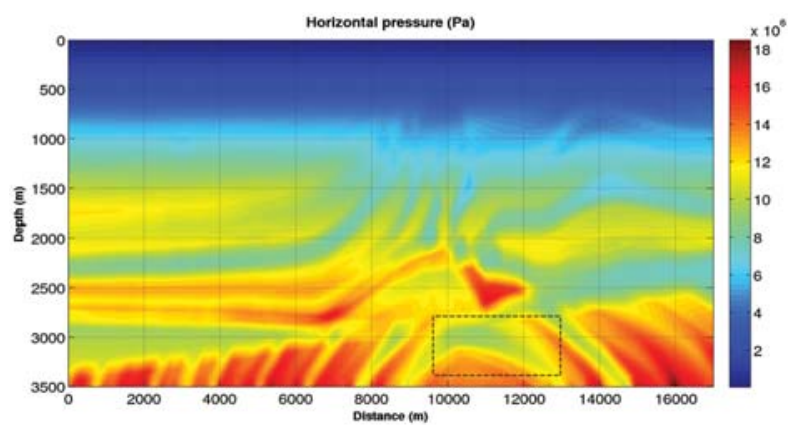

(b) Smoothing with 41 points.

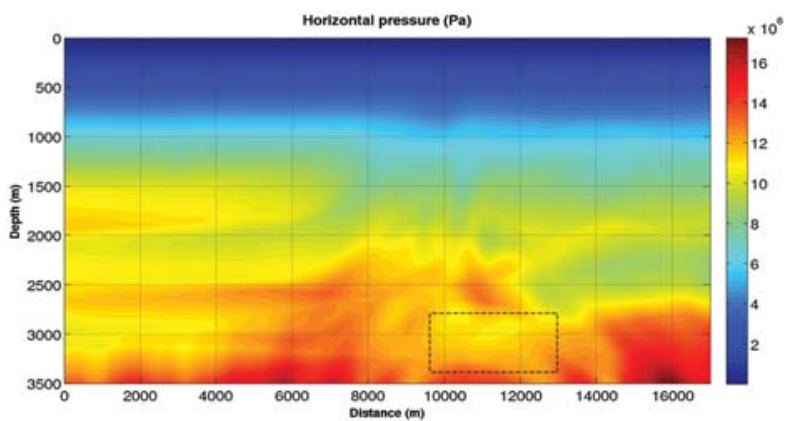

(d) Smoothing with 121 points.

Figure 16 - Horizontal pressure field, $P_{x}(x, z)$. 


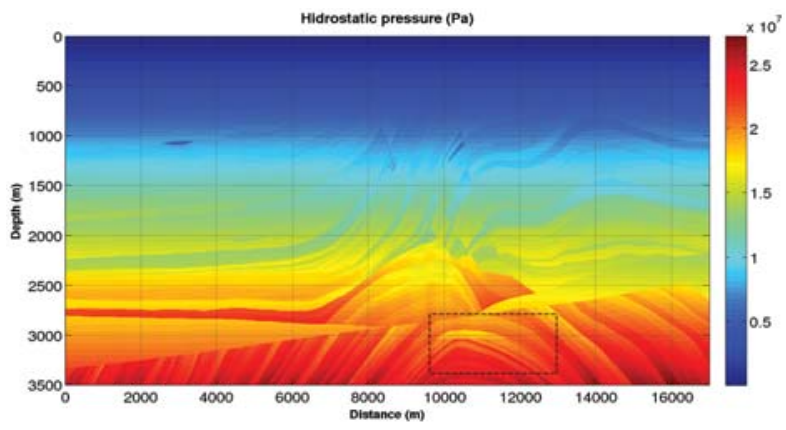

(a) Original model.

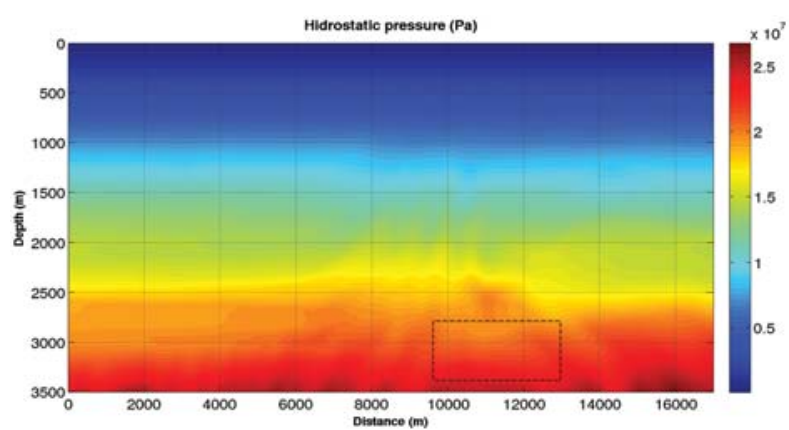

(c) Smoothing with 81 points.

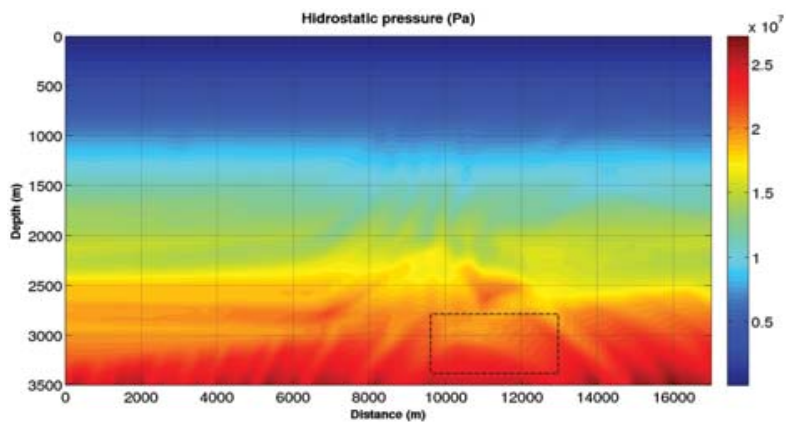

(b) Smoothing with 41 points.

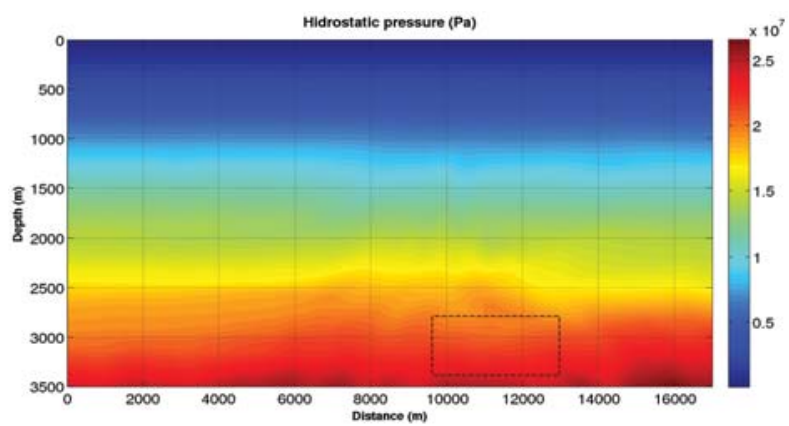

(d) Smoothing with 121 points.

Figure 17 - Hydrostatic pressure field, $P_{H}(x, z)$.

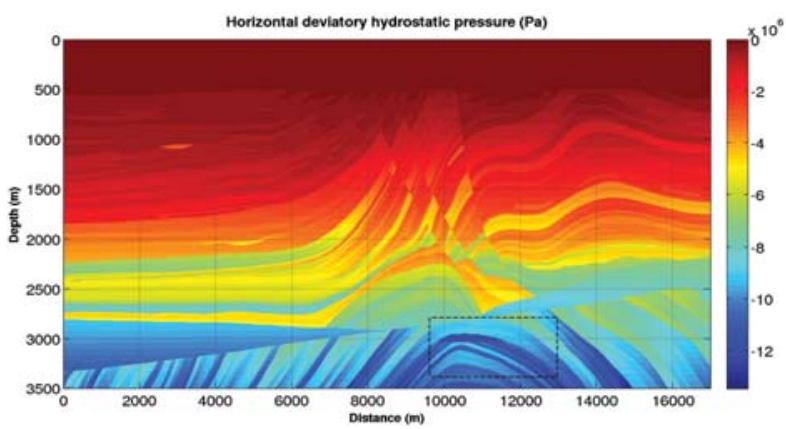

(a) Original model.

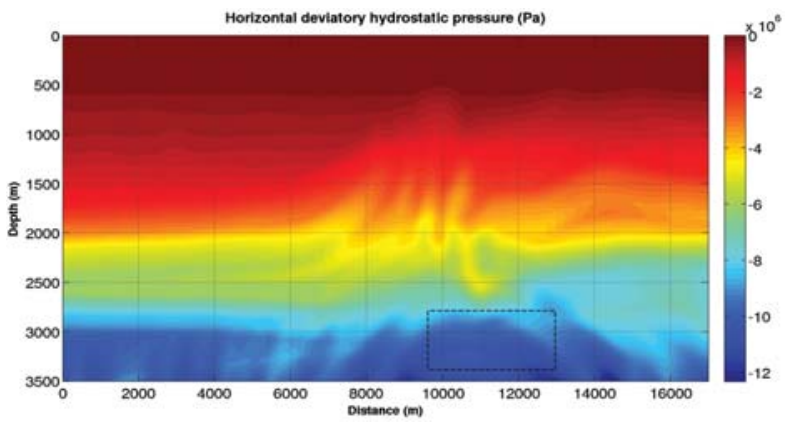

(c) Smoothing with 81 points.

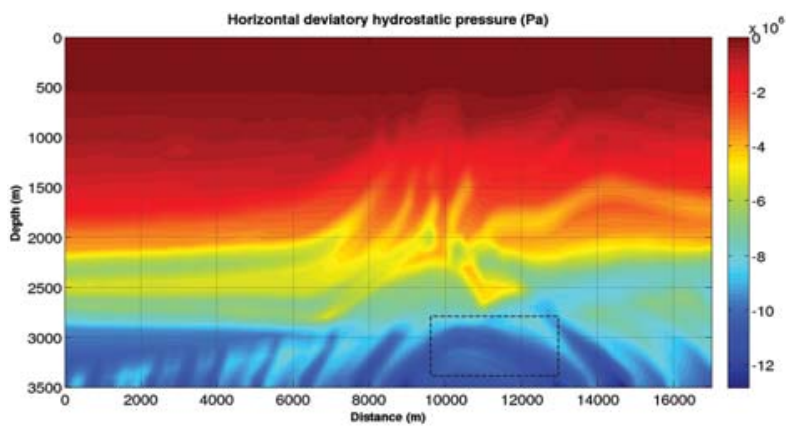

(b) Smoothing with 41 points.

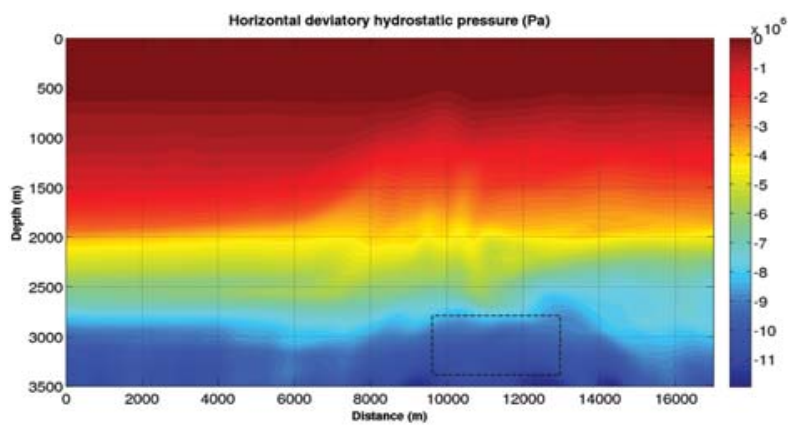

(d) Smoothing with 121 points.

Figure 18 - Horizontal deviatory hydrostatic pressure field, $P_{X H}=\sigma_{x x}-P_{H}$. 


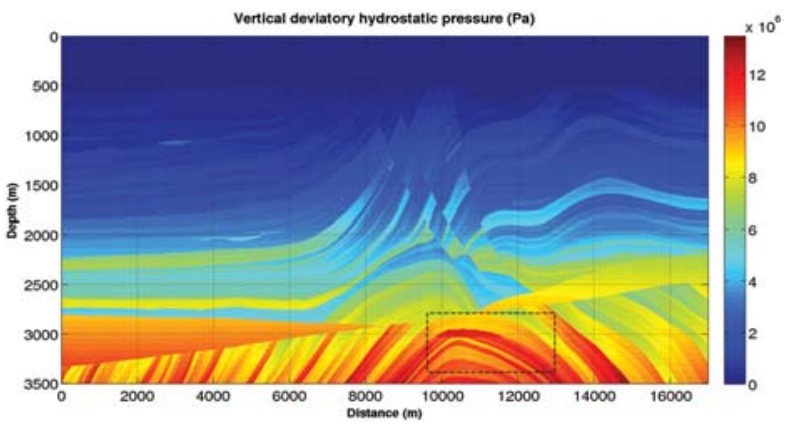

(a) Original model.

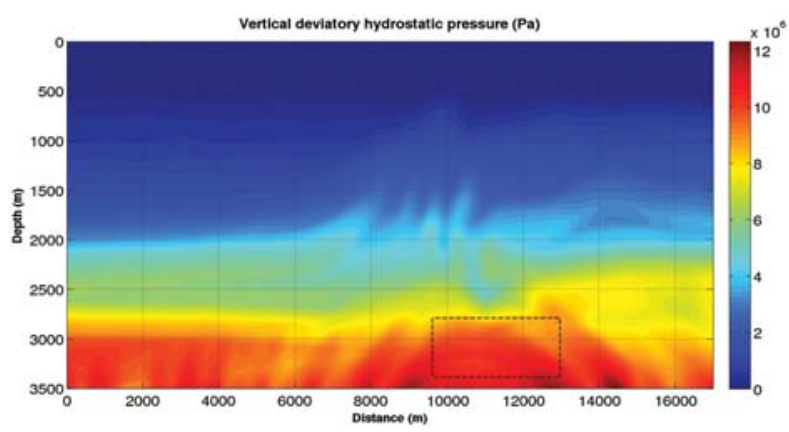

(c) Smoothing with 81 points.

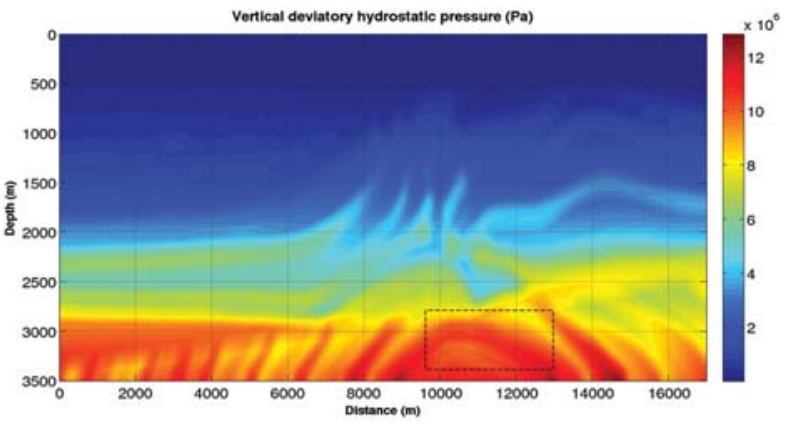

(b) Smoothing with 41 points.

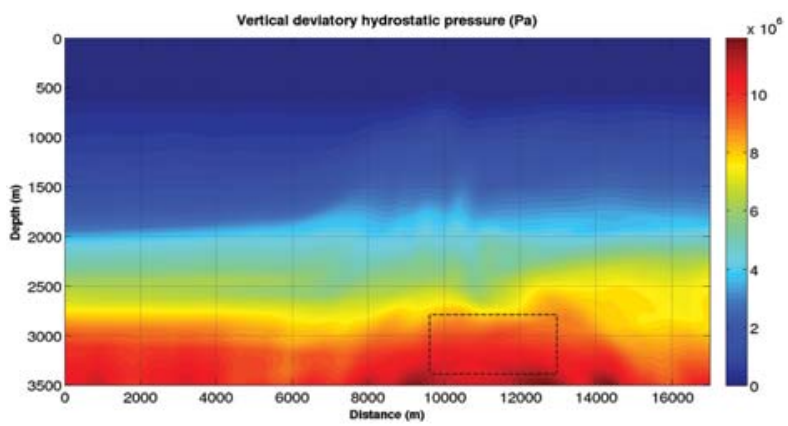

(d) Smoothing with 121 points.

Figure 19 - Vertical deviatory hydrostatic pressure field, $P_{Z H}=\sigma_{z z}-P_{H}$

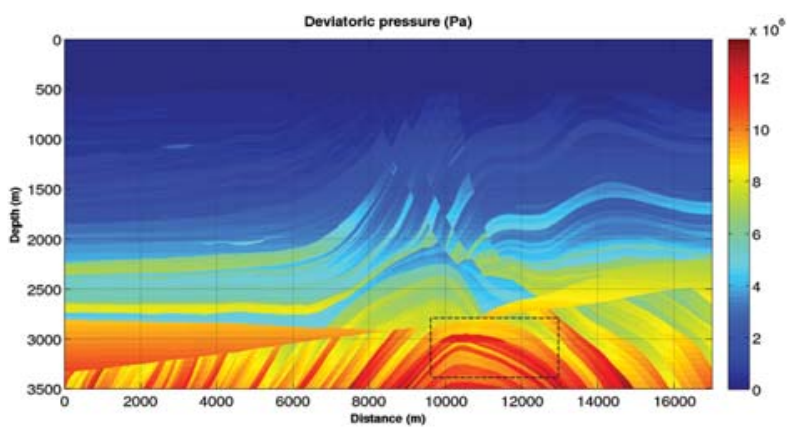

(a) Original model.

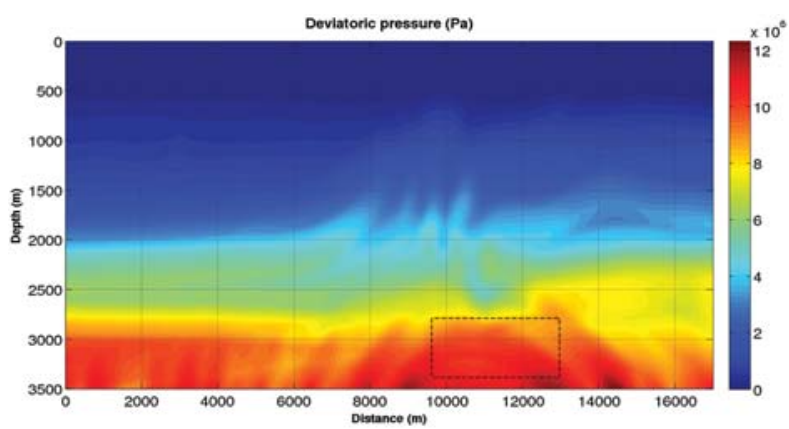

(c) Smoothing with 81 points.

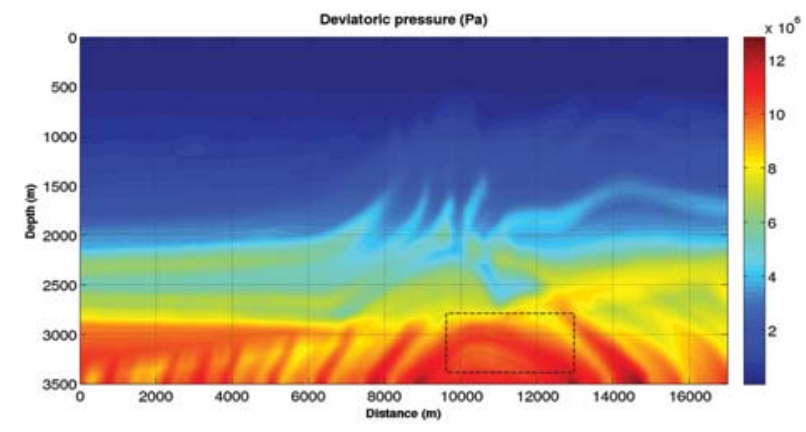

(b) Smoothing with 41 points.

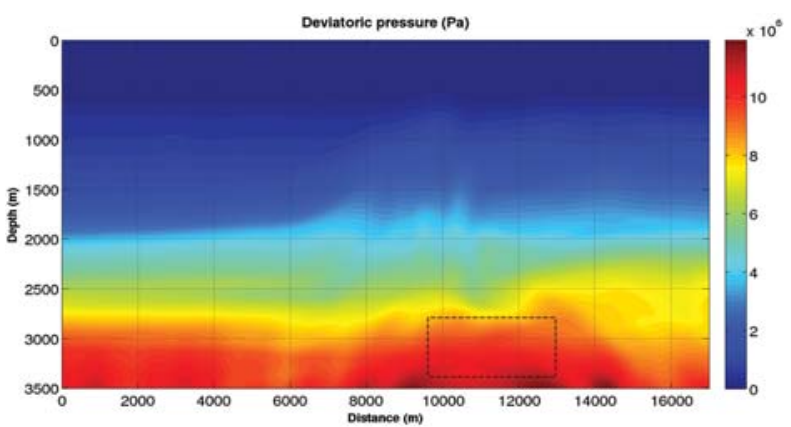

(d) Smoothing with 121 points.

Figure 20 - Tangential deviatory pressure field, $P_{T}(x, z)$. 


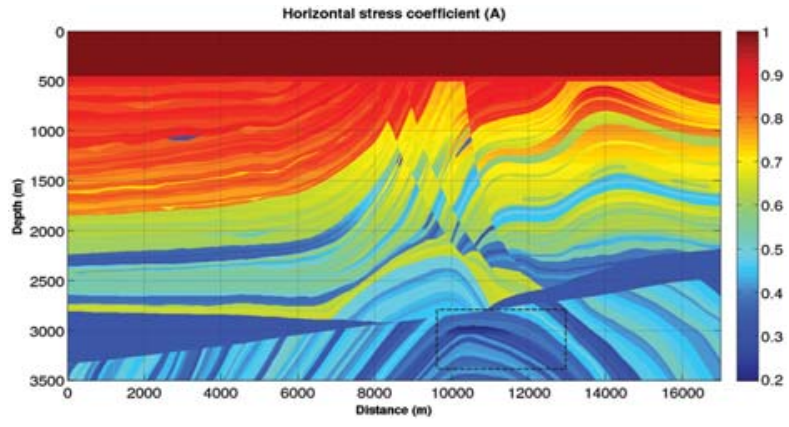

(a) Original model.

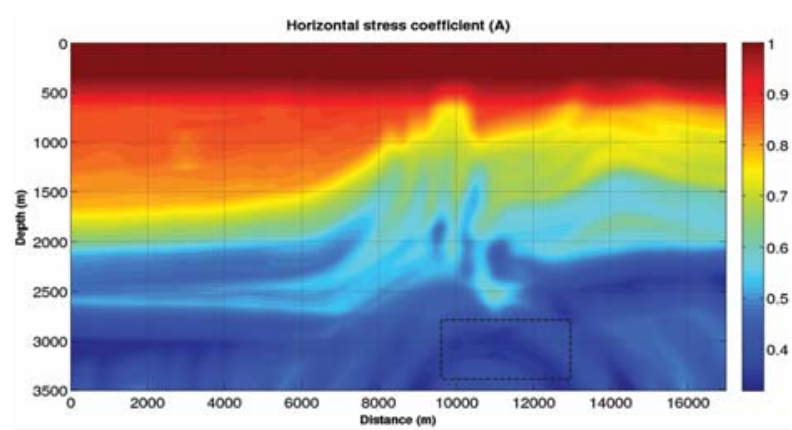

(c) Smoothing with 81 points.

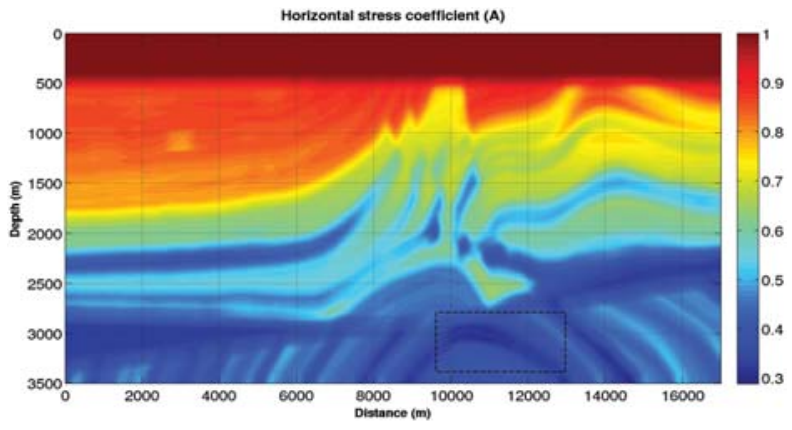

(b) Smoothing with 41 points.

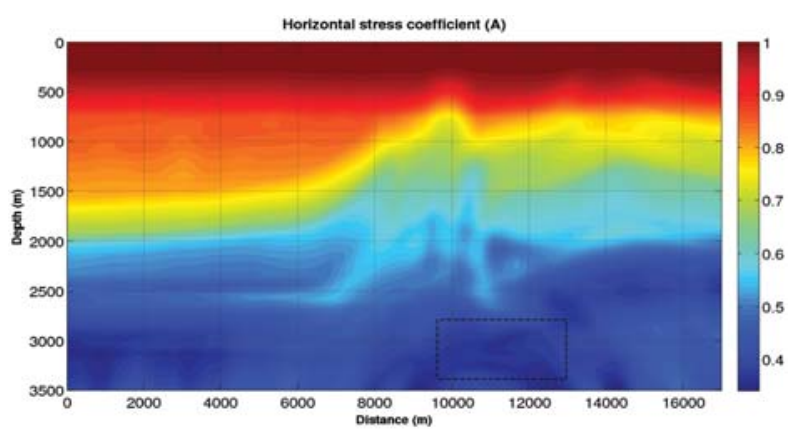

(d) Smoothing with 121 points.

Figure 21 - Horizontal/vertical stress ratio, $k_{x z}(x, z)$.

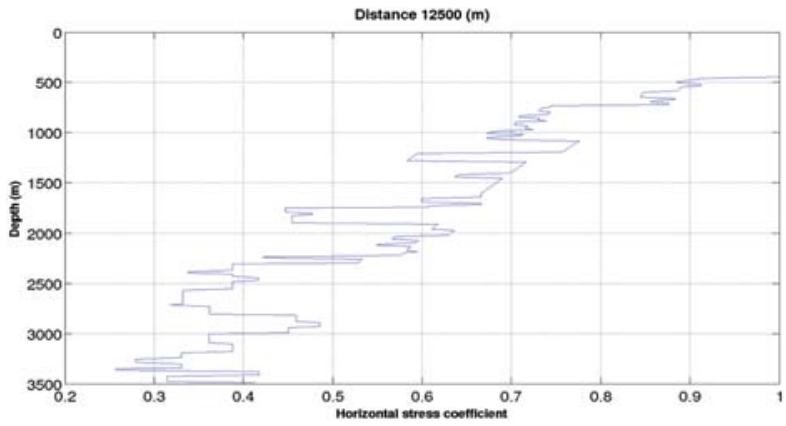

(a) Original model.

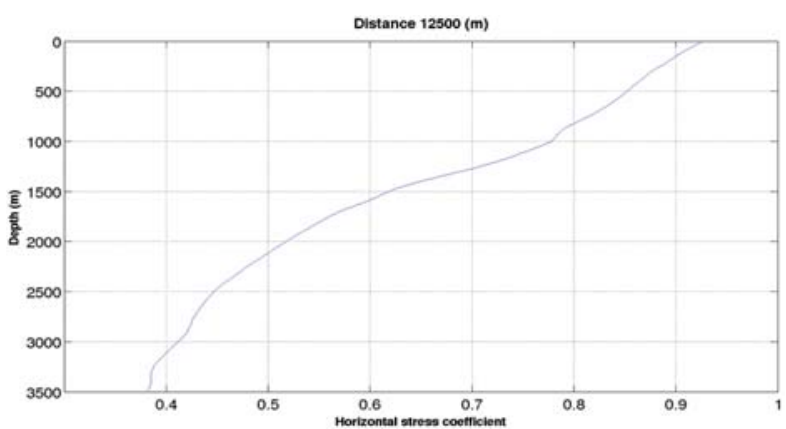

(c) Smoothing with 81 points.

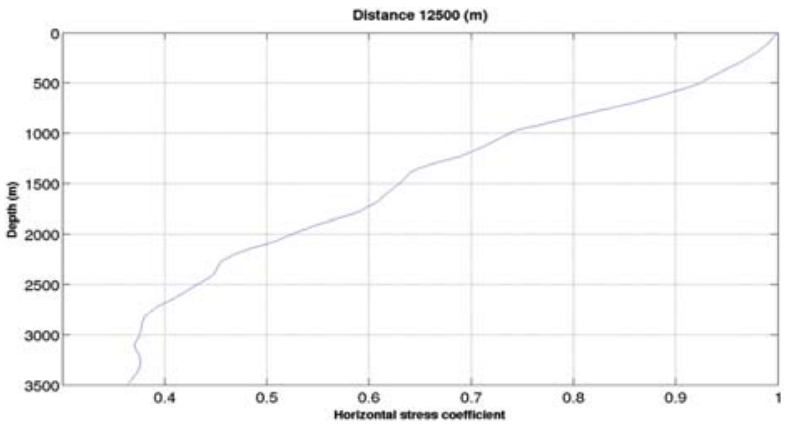

(b) Smoothing with 41 points.

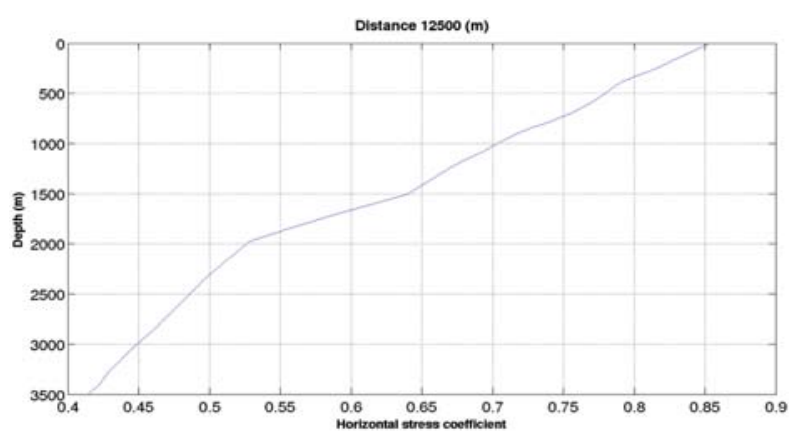

(d) Smoothing with 121 points.

Figure 22 - Horizontal/vertical stress ratio selected profile, $k_{x z}(z)$. 
a randomly chosen CDP at the coordinate of $12.500 \mathrm{~m}$. The top left figure shows a vertical variation with superimposed strong oscillations, that clearly disappear with the smoothing process, and shows a linear to an exponential trend behavior. The scale shows the interval variation for $0.2<k_{x z}(z)<1$, where Heim's rule is still being supported as $\sigma_{x x} \neq \sigma_{z z}$.

Figure 23 shows the vertical pressure discontinuities calculated by Eq. (25). In this special figure, we can identify the geological sequences of the model, and it also shows clearly details of the target reservoir as the smoothing increases. This is also another important conclusion of these numerical experiments.

Figure 24 shows the rate of vertical variation of the vertical pressure field calculated by a numerical derivative. Following the analysis for the correspondent vertical pressure field in Figure 15, this figure also exhibit a difficulty to identify the target reservoir in the structure as the smoothing process increases.

Figure 25 shows the rate of horizontal variation of horizontal pressure calculated by a numerical derivative. This figure exhibits an interesting behavior, and opposite to the other ones, since and it recovers aspects of the structure and discontinuities as the smoothing increases. Therefore, it serves also as a main conclusion in this work.

\section{CONCLUSIONS}

The conclusions are related to the main goal established by the initial question on how sensitive is the pressure prediction to the variation of velocity and density distributions, principally around a geological reservoir zone, with the results presented in the form of depth sections for the geological domain.

In situ measurement of stress is described to be very important in several fields of engineering, geology and geophysics aiming at several applications, and here we are concerned with oil and gas exploration (Amadei \& Stephansson, 1997).

We showed details of the theorectical model, and used an important example to show how pressure varies in the subsurface of the synthetic classical Marmousi model. In order words, we showed that the prediction of pressure does not necessarily increases linearly, but in a complex form. The marked target by a spatial window identifies a confined low pressure zone representing the reservoir, but other low pressure areas are also mapped.

As a detail, the present theorectical model imposes the stress agent as the vertical gravity load of the geological rock formations, and does not take into account the reflector's curvatures, faulting and diagenesis.

Stress and pressure prediction is an important issue for the analysis of a sedimentary basins, aiming at oil and gas poten- tially more productive areas. But the prediction needs a 3D model for its complete meaningful application (Brown, 2011).

The sensitivity analysis to measure the decay in the resolution of the stress state prediction in this example followed the migration methodology, and the main conclusions are listed below.

- The horizontal pressure field in Figure 16 exhibits details of the target reservoir in the geological structure as the smoothing process increases, and it is one of the main results obtained here.

- The vertical pressure discontinuities in Figure 23 allows the identification of the geological sequences, and clearly shows details of the target confined reservoir as the smoothing process increases. This is also a special result in this work.

- The horizontal variation of the horizontal pressure field in Figure 25 exhibits an interesting behavior opposite to the other figures commented above, and where the structures and discontinuities become clearer as the smoothing process increases. Due to this finding, it serves as a main conclusion from these numerical experiments.

- In this numerical experiment simulating a real case showed that all figures and concepts were useful as control tools in the modeling of sedimentary basins for oil and gas exploration. Also, following the specialized literature, other figure constructions can be added, but would make the paper too long.

To end, this paper dealt with a potential application of a methodology to help the analyses of productive reservoirs, but the method needs a greater amount of information; namely, the $v_{\mathrm{P}}(\mathbf{x}), v_{\mathrm{S}}(\mathbf{x})$ and $\rho(\mathbf{x})$, that is based on $3 \mathrm{D}$ survey and $3 \mathrm{D}$ component seismic data, or on alternative techniques like VSP, AVO and petrophysics.

\section{ACKNOWLEDGEMENTS}

First, the authors would like to thank the reviewers for their patience and positive contributions. The authors also would like to thank the Brazilian institutions UFPA (Universidade Federal do Pará), FINEP (Financiadora de Estudos e Projetos, Fase 5), and to the project National Institute of Science and Technology (Instituto Nacional de Ciência e Tecnologia, INCT-GP, of MCT/CNPq/FINEP) for the research support aiming at oil exploration. The thanks are also extended to CAPES for the scholarship. Special thanks go to the project Science Without Borders of CAPES/CNPq of the Brazilian Federal Government that 


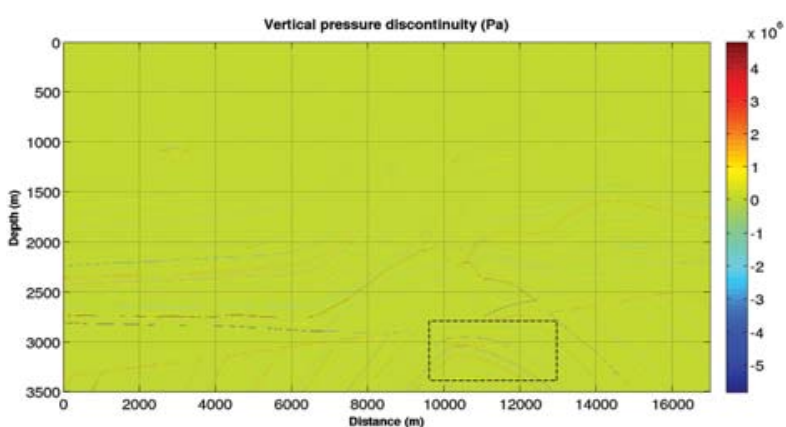

(a) Original model.

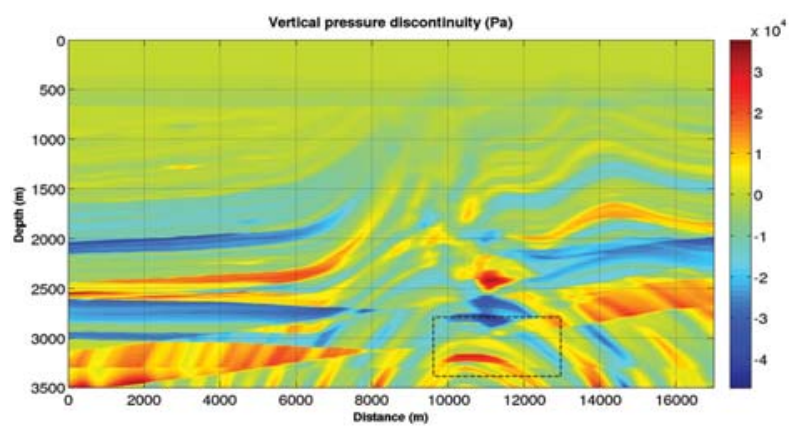

(c) Smoothing with 81 points.

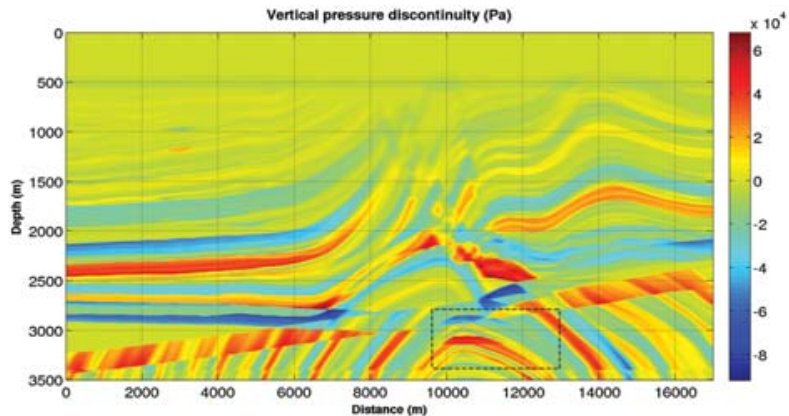

(b) Smoothing with 41 points.

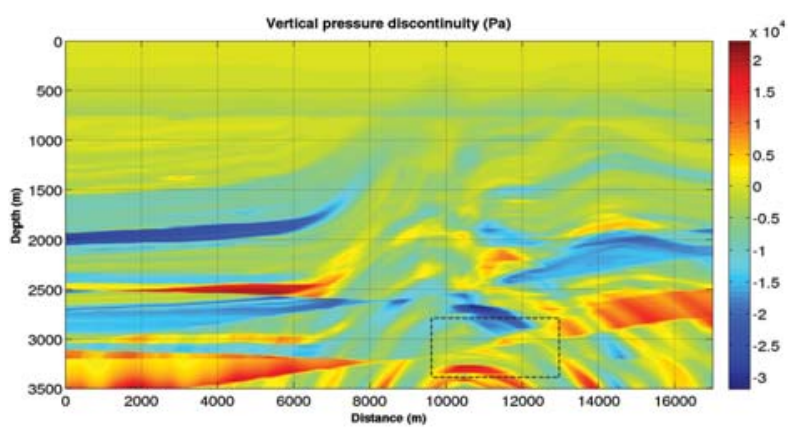

(d) Smoothing with 121 points.

Figure $\mathbf{2 3}$ - Vertical pressure discontinuities, $\Delta P(x, z)$, across the interfaces.

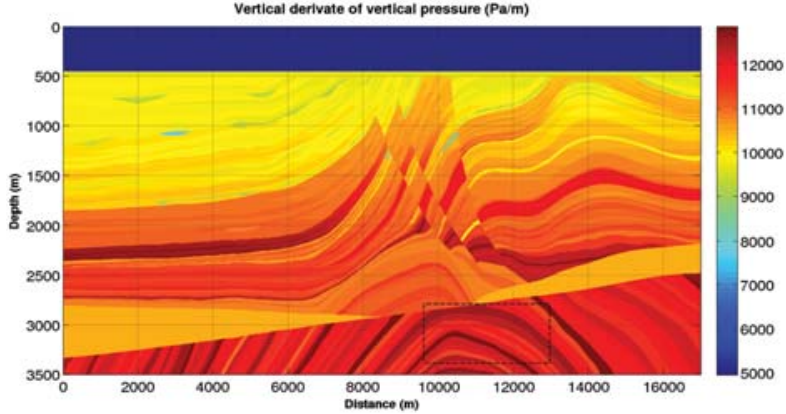

(a) Original model.

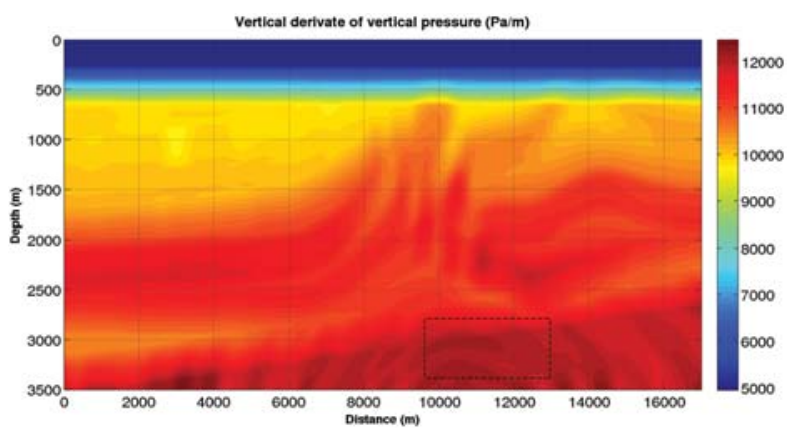

(c) Smoothing with 81 points.

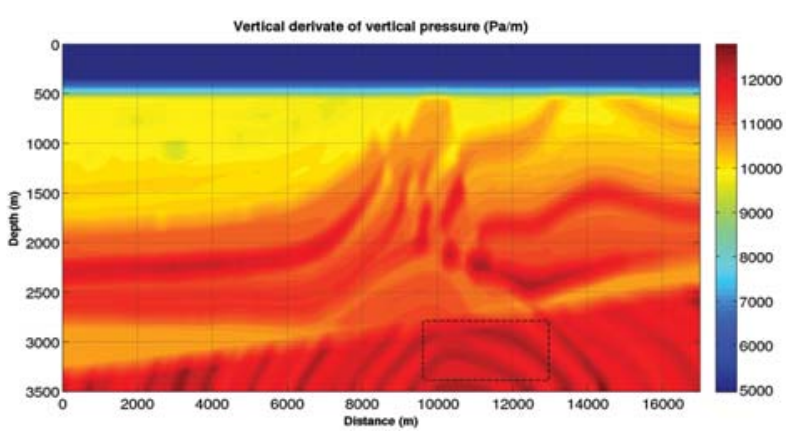

(b) Smoothing with 41 points.

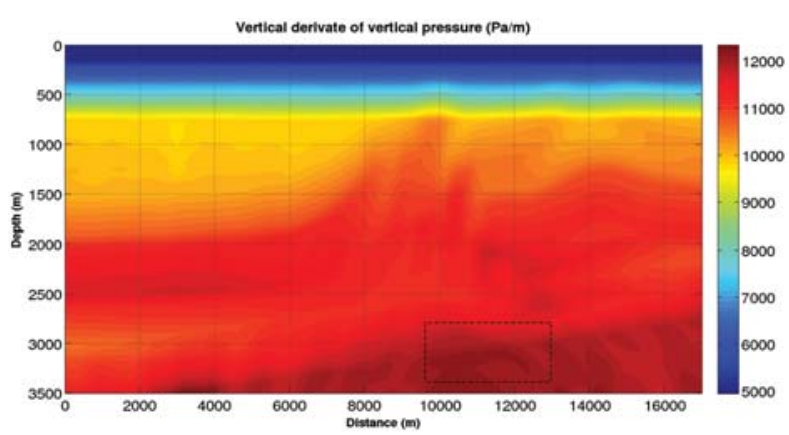

(d) Smoothing with 121 points.

Figure 24 - Vertical variation, $\frac{\partial P_{z}(x, z)}{\partial z}$, of the vertical pressure field given in Figure 15. 


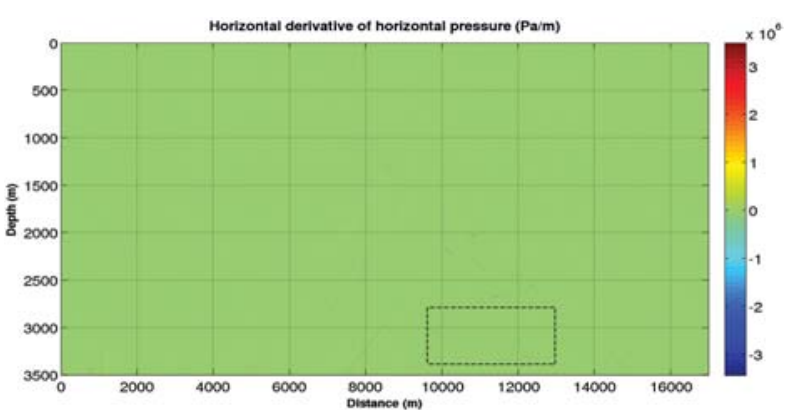

(a) Original model.

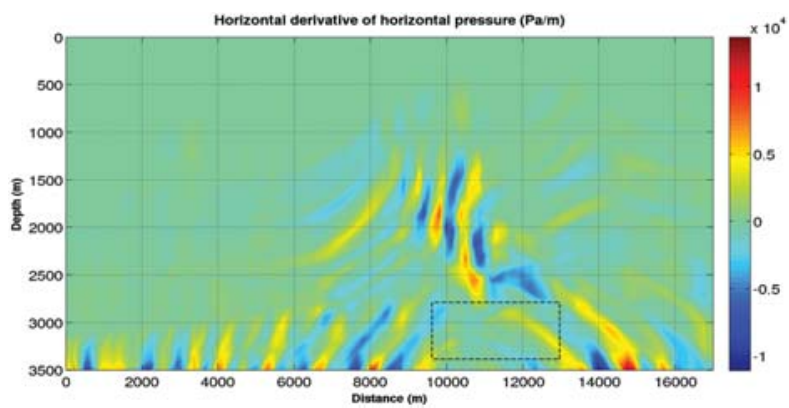

(c) Smoothing with 81 points.

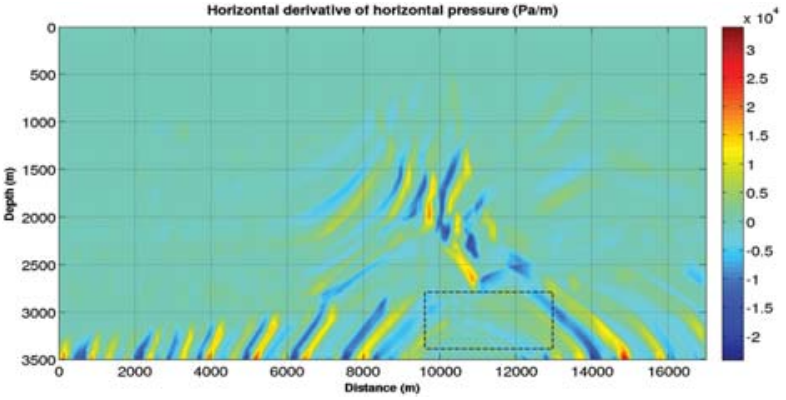

(b) Smoothing with 41 points.

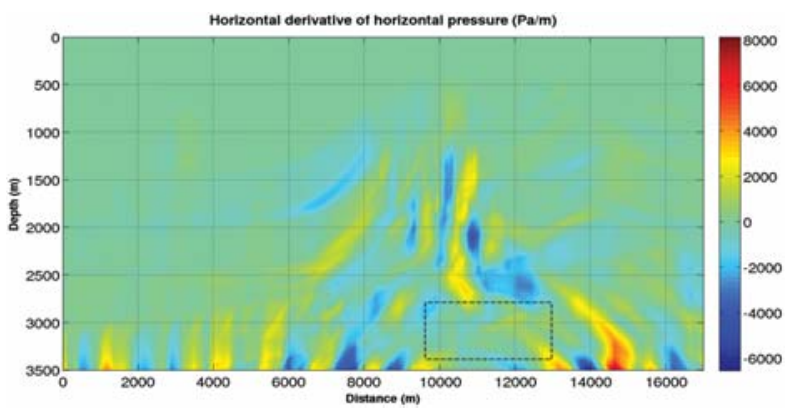

(d) Smoothing with 121 points.

Figure $\mathbf{2 5}$ - Vertical variation, $\frac{\partial P_{x}(x, z)}{\partial z}$, of the horizontal pressure field given in Figure 16.

sponsors a main part of this research work developed at UFPA/IG/CPGF.

\section{REFERENCES}

ABRAMOWITZ M \& STEGUN IA. 1970. Handbook of mathematical functions. Dover Publications, Inc., New York.

AMADEI B \& STEPHANSSON 0. 1997. Rock Stress and Its Measurement. Springer Science, London, England.

AMEEM MS. 2003. Fracture and In-Situ Stress Characterization of Hydrocarbon Reservoirs. The Geological Society of London, London.

BIONDI LB. 2010. 3D seismic imaging. Society of Exploration Geophysicists, Tulsa, OK, USA.

BROWN A. 2011. Interpretation of three-dimensional seismic data, volume AAPG Memoir 42. Society of Exploration Geophysicists, Tulsa, OK, USA.

COHEN JK \& STOCKWELL JJW. 2005. CWP/SU: Seismic Un*x Release 39 - a free package for seismic research and processing. Center for Wave Phenomena, Colorado School of Mines. 153 pp.

FRANK PM. 1978. Introduction to System Sensitivity Theory. Academic Press.
GALPERIN EI. 1985. Vertical seismic profiling and its exploration potential. D. Reidel Publishing Company, Boston.

HANTSCHEL T \& KAUERAUF Al. 2009. Fundamentals of Basin and Petroleum Systems Modeling. Springer-Verlag, Berlin.

HARDAGE BA, DEANGELO MV, MURRAY PE \& SAVA D. 2011. Multicomponent seismic technology. Society of Exploration Geophysicists, Tulsa, OK, USA.

LOWRIE W. 2011. A Student's guide to Geophysical Equations. Cambridge University Press, London.

MARTIN GS, WILEY R \& MARFURT KJ. 2006. Marmousi2: An elastic upgrade for Marmousi. The Leading Edge. SEG., 156-166.

MAVKO G, MUKERJI T \& DVORKIN J. 1999. The rock physics handbook. Cambridge University Press, London. 340 pp.

NELSON RA. 2001. Geologic Analysis of Naturally Fractured Reservoirs. Gulf Professional Publishing, Boston, USA.

PERSEN LN. 1975. Rock Dynamics and Geophysical Exploration. Elsevier Scientific Publishing Company, Amsterdam, Holland.

REEVES G. 2009. Smooth2a. Division of Biology, Caltech, USA, version 1.0 .

SCHILLING RJ \& HARRIS SL. 2005. Fundamentals of Digital Signal Processing Using MATLAB. Cengage. 
SIBIRYAKOV EP, LEITE LWB \& VIEIRA WWS. 2014. Model of the structured continuum, and the relation between specific surface area, porosity and permeability. Brazilian Journal of Geophysics, 31(4): 559-568.

SIBIRYAKOV EP, LEITE LWB, SIBIRYAKOV E \& VIEIRA WWS. 2015a. Local low pressure areas in anticline structures. Brazilian Journal of Geophysics, 33(2): 225-236.

SIBIRYAKOVEP, LEITE LWB \& VIEIRA WWS. 2015b. Behavior of stresses in structures and the effect on hydrodynamics analyzed from multicom- ponent seismic data. Brazilian Journal of Geophysics, 33(1): 57-70.

SMIRNOV VI. 1964. Course of higher Mathematics. Volume 2. Pergamon Press, London.

VERSTEEG R \& GRAU G. 1991. The Marmousi experience. In: Proc. EAGE Workshop on Practical Aspects of Seismic Data Inversion. Copenhagen.

ZANG A \& STEPHANSSON 0. 2010. Stress Field of the Earth's Crust. Springer-Verlag, Berlin. 